\title{
Extracellular Superoxide Dismutase Attenuates Renal Oxidative Stress Through the Activation of Adenosine Monophosphate-Activated Protein Kinase in Diabetic Nephropathy
}

\author{
Yu Ah Hong, Ji Hee Lim,, Min Young Kim,1 Yaeni Kim,, Hoon Suk Park, Hyung Wook Kim, \\ Bum Soon Choi, ${ }^{1}$ Yoon Sik Chang, ${ }^{1}$ Hye Won Kim, ${ }^{2}$ Tae-Yoon Kim, ${ }^{3}$ and Cheol Whee Park ${ }^{1}$
}

\begin{abstract}
Aims: Oxidative stress plays a crucial role in the pathogenesis of diabetic nephropathy (DN). We evaluated whether extracellular superoxide dismutase (EC-SOD) has a renoprotective effect through activation of adenosine monophosphate-activated protein kinase (AMPK) in diabetic kidneys.

Results: Human recombinant EC-SOD (hEC-SOD) was administered to 8-week-old male C57BLKS/J $d b / d b$ mice through intraperitoneal injection once a week for 8 weeks. Renal SOD3 expression was suppressed in $d b / d b$ mice, which was significantly enhanced by hEC-SOD treatment. hEC-SOD improved albuminuria, mesangial expansion, and interstitial fibrosis in $d b / d b$ mice. At the molecular level, hEC-SOD increased phosphorylation of AMPK, activation of peroxisome proliferative-activated receptor $\gamma$ coactivator $1 \alpha(\mathrm{PGC}-1 \alpha)$, and dephosphorylation of forkhead box $\mathrm{O}$ transcription factor (FoxO) 1 and FoxO3a. The protective effects of hEC-SOD were attributed to enhanced nuclear translocation of nuclear factor E2-related factor 2 (Nrf2) and subsequently increased expression of $\mathrm{NAD}(\mathrm{P}) \mathrm{H}$ dehydrogenase 1 and heme oxygenase-1. Consequently, hEC-SOD recovered from systemic and renal inflammation and apoptosis, as reflected by the decreases of serum and renal monocyte chemoattractant protein-1 and tumor necrosis factor- $\alpha$ levels and increases of BCL-2/BAX ratio in diabetic kidney. hEC-SOD also improved oxidative stress and resulted in increased renal and urinary 8-hydroxy-2'-deoxyguanosine and 8-isoprostane levels in $d b / d b$ mice. In cultured human glomerular endothelial cells, hEC-SOD ameliorated apoptosis and oxidative stress caused by high glucose exposure through activation of AMPK and PGC- $1 \alpha$ and dephosphorylation of FoxOs. Innovation: These findings demonstrated for the first time that EC-SOD can potentially ameliorate hyperglycemia-induced oxidative stress, apoptosis, and inflammation through activation of AMPK and its downstream pathways in diabetic kidneys.
\end{abstract}

Conclusions: EC-SOD is a potential therapeutic target for treatment of type 2 DN through intrarenal AMPKPGC-1 $\alpha$-Nrf2 and AMPK-FoxOs signaling. Antioxid. Redox Signal. 28, 1543-1561.

Keywords: adenosine monophosphate-activated protein kinase, diabetic nephropathy, extracellular superoxide dismutase, oxidative stress, inflammation, apoptosis

\section{Introduction}

D IABETIC NEPHROPATHY (DN) Is a serious microvascular complication of diabetes and the major cause of endstage renal disease worldwide, including in Korea (23).
Accumulated advanced glycated end products; activation of polyol pathways, renin-angiotensin system, and the protein kinase $\mathrm{C}$ pathway; and increased oxidative stress play crucial roles in the development of DN $(4,22)$. Among these various causes, reactive oxygen species (ROS) and reactive

\footnotetext{
${ }^{1}$ Division of Nephrology, Department of Internal Medicine, The Catholic University of Korea, Seoul, Republic of Korea. Departments of ${ }^{2}$ Rehabilitation and ${ }^{3}$ Dermatology, The Catholic University of Korea, Seoul, Republic of Korea.
} 


\section{Innovation}

Oxidative stress plays a critical role in the development and progression of diabetic nephropathy (DN). To date, the role of extracellular superoxide dismutase (EC-SOD) in DN remains controversial. This study demonstrated that EC-SOD has an important role in the improvement of oxidative stress, apoptosis, and inflammation in DN. Furthermore, adenosine monophosphate-activated protein kinase (AMPK) is directly phosphorylated by EC-SOD activation, and the activation of AMPK and its downstream targets ameliorates diabetic kidney injury. This is the first demonstration that EC-SOD attenuates renal oxidative stress through intrarenal AMPK-PGC- $1 \alpha-\mathrm{Nrf} 2$ and AMPK-FoxOs signaling in DN. EC-SOD can be a potential therapeutic target for treatment of DN.

nitrogen species (RNS) are of paramount importance in DN (42). Glucose oxidation in medullary segments and free fatty acid oxidation are the main sources of increased production of ROS and RNS, which are important secondary messengers for signaling pathways associated with apoptosis and inflammation, especially in DN (16).

Superoxide dismutase (SOD) is the major antioxidant enzyme, and it converts superoxide into hydrogen peroxide and molecular oxygen (11). Mammals have three distinct forms of SOD, which are characterized by their metal ions and localizations. Copper, zinc SOD (SOD1) is found in the cytosol, and manganese SOD (SOD2) is located in the mitochondria. Extracellular SOD (EC-SOD or SOD3) exists primarily in the extracellular space and is believed to have a special role in tissue homeostasis within extracellular locations $(8,9)$.

Adenosine monophosphate-activated protein kinase (AMPK), the downstream target of a protein kinase cascade acting as an intracellular energy sensor, regulates energy stresses that cause imbalance in the AMP/ATP ratio (18). AMPK promotes cell survival by inducing autophagy, mitochondrial biogenesis, and antioxidant defense systems through downstream signaling pathways, including peroxisome proliferatoractivated receptor $\gamma$ coactivator $1 \alpha$ (PGC- $1 \alpha)$, forkhead box $\mathrm{O}$ transcription factor (FoxO), mammalian target of rapamycin, and silent information regulator $1(5,21,41)$. Transcriptional regulation of PGC- $1 \alpha$ is responsible for the upregulation of mitochondrial biogenesis-related genes in response to ROS produced by mitochondrial dysfunction (5, 21). PGC- $1 \alpha$ also acts upstream of the nuclear factor E2related factor 2 (Nrf2)-antioxidant response element pathway to increase transcription of $\mathrm{Nrf2}$ (30). Nrf2 regulates cellular detoxification responses and redox status in chronic kidney disease and DN $(2,25)$. EC-SOD is mainly synthesized by vascular smooth muscle cells and fibroblasts (44). Although ECSOD is mostly made by vascular smooth muscle cells rather than endothelial cells, it binds to the extracellular matrix on endothelial cell surfaces and can be internalized by endothelial cells $(6,40)$. Glomerular endothelial cell injury plays a major role in the development of $\mathrm{DN}$ and can lead to podocyte damage, ultimately resulting in glomerulotubular damage (12). EC-SOD is most widely expressed in the kidney (13). However, the role of EC-SOD in DN remains controversial.
We previously reported that several AMPK activators ameliorate the severity of DN through improved oxidative stress by activating AMPK and its downstream signal pathways $(20,26,29)$. However, evidence regarding the renoprotective effects of EC-SOD through activation of AMPK in $\mathrm{DN}$ is poorly understood. We hypothesized that human recombinant EC-SOD (hEC-SOD) can potentially ameliorate renal hyperglycemia-induced oxidative stress, inflammation, and apoptosis through the activation of AMPK-PGC- $1 \alpha-\mathrm{Nrf} 2$ and AMPK-FoxOs pathways.

\section{Results}

\section{Biochemical and physiological parameters of mice}

The body weight of $d b / d b$ mice was significantly higher than that of $\mathrm{db} / \mathrm{m}$ and $\mathrm{db} / \mathrm{m}$ hEC-SOD mice and decreased in $d b / d b$ hEC-SOD mice. HbA1c and fasting blood glucose levels were markedly higher for $d b / d b$ and $d b / d b$ hEC-SOD mice than for $d b / m$ and $d b / m$ hEC-SOD mice. Administration of hEC-SOD did not influence blood glucose levels in diabetic mice. There were no differences in kidney weight, blood urea nitrogen, or serum creatinine level among the study groups. Urine volume and albuminuria were further increased in $d b / d b$ mice, and administration of hEC-SOD ameliorated $24 \mathrm{~h}$ albuminuria and urine volume in $\mathrm{db} / \mathrm{db}$ mice (Table 1).

\section{Effects of hEC-SOD on renal histological changes and expression of transforming growth factor- $\beta 1$ and $\mathrm{Col} I \mathrm{~V}$}

Mesangial expansion and tubulointerstitial fibrosis are the main causes of deteriorating renal function in DN (38). Fractional mesangial area was not different between $\mathrm{db} / \mathrm{m}$ and $d b / m$ hEC-SOD mice, and further increased in $d b / d b$ mice (Fig. 1A, B, $p<0.001$ ). Interstitial fibrotic area and expression of transforming growth factor- $\beta 1$ (TGF- $\beta 1$ ) and type IV collagen (Col IV) were also largely increased in $\mathrm{db}$ / $d b$ mice compared with $d b / m$ and $d b / m$ hEC-SOD mice (Fig. 1A, C-E, $p<0.001, p<0.01$, and $p<0.01$, respectively). All diabetes-induced renal histological changes and expression of TGF- $\beta 1$ and Col IV seen in $d b / d b$ mice were recovered by hEC-SOD treatment.

\section{Effects of hEC-SOD on intrarenal SOD isoform and renal expression of SOD3}

The intrarenal SOD contents were determined and are shown in Figure 2. The SOD1 and SOD2 levels were markedly suppressed in $\mathrm{db} / \mathrm{db}$ mice compared with those in $\mathrm{db} / \mathrm{m}$ and $\mathrm{db} / \mathrm{m}$ hEC-SOD mice (Fig. 2A-C, $p<0.001$ and $p<0.001$, respectively). Administration of hEC-SOD to $\mathrm{db} /$ $d b$ mice did not restore SOD1 and SOD2 to the levels of those in $\mathrm{db} / \mathrm{m}$ and $\mathrm{db} / \mathrm{m}$ hEC-SOD mice. The SOD3 level was lower in $d b / d b$ mice than in $d b / m$ and $d b / m$ hEC-SOD mice, and it was significantly enhanced in $d b / d b$ mice treated with hECSOD (Fig. 2A, D, $p<0.01$ ). The intensity of SOD3 measured by immunofluorescence staining was significantly higher in both tubules and glomeruli of kidneys from $d b / d b$ hEC-SOD mice than in those from $d b / d b$ mice (Fig. 2E). These findings suggest that hEC-SOD treatment can recover expression of SOD3, but not SOD1 and SOD2, in diabetic kidneys. 
Table 1. Biochemical and Physical Characteristics of the Four Groups at the End of the 16 WeEks Experimental Period

\begin{tabular}{lcccc}
\hline & $\mathrm{db} / \mathrm{m}$ Control & $\mathrm{db} / \mathrm{m}$ hEC-SOD & $\mathrm{db} / \mathrm{db}$ Control & $\mathrm{db} / \mathrm{db}$ hEC-SOD \\
\hline Body weight $(\mathrm{g})$ & $30.7 \pm 1.6$ & $30.1 \pm 0.8$ & $55.8 \pm 4.5^{\dagger}$ & $40.4 \pm 4^{\S}$ \\
Kidney weight $(\mathrm{g})$ & $0.19 \pm 0.02$ & $0.21 \pm 0.03$ & $0.21 \pm 0.04$ & $0.21 \pm 0.04$ \\
FBS (mg/dL) & $150.8 \pm 42.2$ & $139.6 \pm 23.4$ & $577.3 \pm 49.2^{\dagger}$ & $551 \pm 13.5^{\dagger}$ \\
HbA1c (\%) & $4.2 \pm 0.2$ & $3.9 \pm 0.1$ & $13 \pm 1.3^{\dagger}$ & $12.2 \pm 0.6^{\dagger}$ \\
24h Albuminuria ( $\mu$ g/day) & $9.4 \pm 4.7$ & $10.8 \pm 7.1$ & $225.3 \pm 99.9^{\dagger}$ & $61.9 \pm 61^{\ddagger}$ \\
Urine volume (mL/day) & $1.0 \pm 0.3$ & $0.9 \pm 0.3$ & $13.4 \pm 4.5^{\dagger}$ & $8.7 \pm 3.3^{\dagger}$ \\
BUN (mg/dL) & $17.8 \pm 1.9$ & $19.5 \pm 3.6$ & $18.7 \pm 1.2$ & $20.5 \pm 2.3$ \\
Serum Cr $(\mu$ mol/L) & $17.3 \pm 2.9$ & $18.1 \pm 2.5$ & $20.1 \pm 3.4$ & $19.8 \pm 3.3$ \\
Cr clearance (mL/min) & $0.35 \pm 0.18$ & $0.34 \pm 0.20$ & $0.53 \pm 0.19^{*}$ & $0.44 \pm 0.23^{*}$ \\
\hline
\end{tabular}

BUN, blood urea nitrogen; Cr, Creatinine; FBS, fasting blood sugar; EC-SOD, extracellular superoxide dismutase; hEC-SOD, human recombinant EC-SOD. Data are means \pm SD. $n=6-8$ in each groups, ${ }^{*} p<0.05,{ }^{\dagger} p<0.001$ compared with $d b / m$ control and $d b / m$ hEC-SOD groups, and ${ }^{\ddagger} p<0.05,{ }_{p}^{8} p<0.01$ compared with $d b / d b$ control.

Renal expression levels of phospho/total-AMPK,

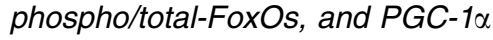

Diabetes markedly reduced phospho-Thr ${ }^{172} /$ total-AMPK expression in $d b / d b$ mice compared with that of $d b / m$ and $d b /$ $m$ hEC-SOD mice (Fig. 3A, $p<0.01$ ). hEC-SOD treatment in $d b / d b$ mice enhanced phospho-Thr ${ }^{172} /$ total-AMPK levels to the levels of $d b / m$ and $d b / m$ hEC-SOD mice. To investigate changes in AMPK downstream targets, FoxOs family and PGC- $1 \alpha$ expression were examined. As the phospho-Thr ${ }^{172}$ / total-AMPK ratio inhibited, increased phospho-Ser ${ }^{256}$ FoxO1 and phospho-Ser ${ }^{253}$ FoxO3a expression was shown in $d b / d b$ mice, and hEC-SOD treatment markedly attenuated phospho$\mathrm{Se}^{256}$ FoxO1 and phospho-FoxO3a Ser ${ }^{253}$ expression in $d b / d b$ mice (Fig. 3B-D, $p<0.01$ and $p<0.01$ ). Consistent with changes in phospho-Thr ${ }^{172} /$ total-AMPK ratio, expression of PGC- $1 \alpha$ was significantly reduced in $d b / d b$ mice and enhanced with hEC-SOD treatment (Fig. 3B, E, $p<0.001$ ).

\section{Renal expression levels of nuclear and cytoplasmic Nrf2, Keap-1, NQO-1, HO-1, and Nox system}

The effect of hEC-SOD treatment on the Nrf2/Kelch-like ECH-associated protein 1 (Keap1) pathway was next evaluated as one of the downstream targets of AMPK. Expression of nuclear Nrf2 was significantly reduced in $d b / d b$ mice, and hEC-SOD treatment enhanced nuclear Nrf2 expression in $d b /$ $d b$ mice (Fig. 4A, B, $p<0.01$ ). However, there were no notable differences in cytoplasmic/total Nrf2 expression among all experimental groups (Fig. 4A, C). Consistent with the changes in cytoplasmic/total Nrf2, expression of the Nrf2 repressor Keap 1 was not significantly different among the groups (Fig. 4A, D). Expression of $\mathrm{NAD}(\mathrm{P}) \mathrm{H}$ dehydrogenase 1 (NQO-1) and heme oxygenase-1 (HO-1) markedly inhibited in $d b / d b$ mice. hEC-SOD treatment in $d b / d b$ mice recovered expression of NQO-1 and HO-1 to the levels of $d b /$ $m$ and $d b / m$ hEC-SOD mice (Fig. 4A, E, F, $p<0.05$ and $p<0.05$, respectively). NADPH oxidases (Nox) are unique enzymes that may be responsible for large amounts of superoxide and hydrogen peroxide production under various pathological conditions. AMPK also has a key role in regulating the Nox system in diabetic kidney disease. Of the major Nox isoforms that have been identified, we investi- gated Nox1, Nox2, and Nox4 expression evaluated as one of the downstream targets of AMPK. Expression of Nox1, Nox2, and Nox4 was significantly increased in $d b / d b$ mice, and hEC-SOD treatment decreased Nox1, Nox2, and Nox4 expression in $d b / d b$ mice (Fig. 4G-J, $p<0.01, p<0.001$ and $p<0.01$, respectively).

\section{Effects of EC-SOD on MRNA expression levels of AMPK, PGC-1 $\alpha$, and Nrf2}

To find out the changes in the gene expression levels of ampk $\alpha 1$, ampk $\alpha 2, p g c-1 \alpha$, and $n r f 2$ after hEC-SOD treatment in $d b / d b$ mice, the mRNA expression levels of these genes were further investigated with reverse transcription polymerase chain reaction (RT-PCR) analysis (Fig. 5A-E). As expected, the mRNA expression levels of ampk $\alpha 1$, ampk $\alpha 2$, $p g c-1 \alpha$, and $n r f 2$ were significantly suppressed in $d b / d b$ mice, but hEC-SOD treatment in $d b / d b$ mice largely reversed the expression levels of ampk $\alpha 1$, ampk $\alpha 2, p g c-1 \alpha$, and $n r f 2$ to the levels of $\mathrm{db} / \mathrm{m}$ and $\mathrm{db} / \mathrm{m}$ hEC-SOD mice $(p<0.01, p<0.01$, $p<0.05$ and $p<0.05$, respectively).

\section{Effects of EC-SOD on mitochondrial biogenesis}

To elucidate the changes of mitochondria biogenesis associated with the enhancement of PGC- $1 \alpha$ by increasing of EC-SOD, we examined the renal morphology in more detail by transmission electron microscopy (TEM). The amounts of mitochondria measured by electron microscopy were significantly lower in the endothelium from $d b / d b$ mice than those from $d b / m$ mice, but hEC-SOD treatment rescued mitochondrial dysfunction in $d b / d b$ mice (Fig. 5F). These findings suggest that hEC-SOD treatment can improve mitochondrial biogenesis in diabetic kidneys.

\section{Effects of EC-SOD on oxidative stress}

Renal oxidative stress was considerably aggravated in $d b / d b$ mice, reflected by 24-h urinary 8-hydroxy-2'deoxyguanosine (8-OH-dG) and 8-epi-prostaglandin F2 $\alpha$ (8isoprostane) concentrations (Fig. 6A, B, $p<0.001$ and $p<0.001$, respectively). Urinary $8-\mathrm{OH}-\mathrm{dG}$ and 8 -isoprostane concentrations were significantly restored in $d b / d b$ mice undergoing hEC-SOD treatment. Immunohistochemical 

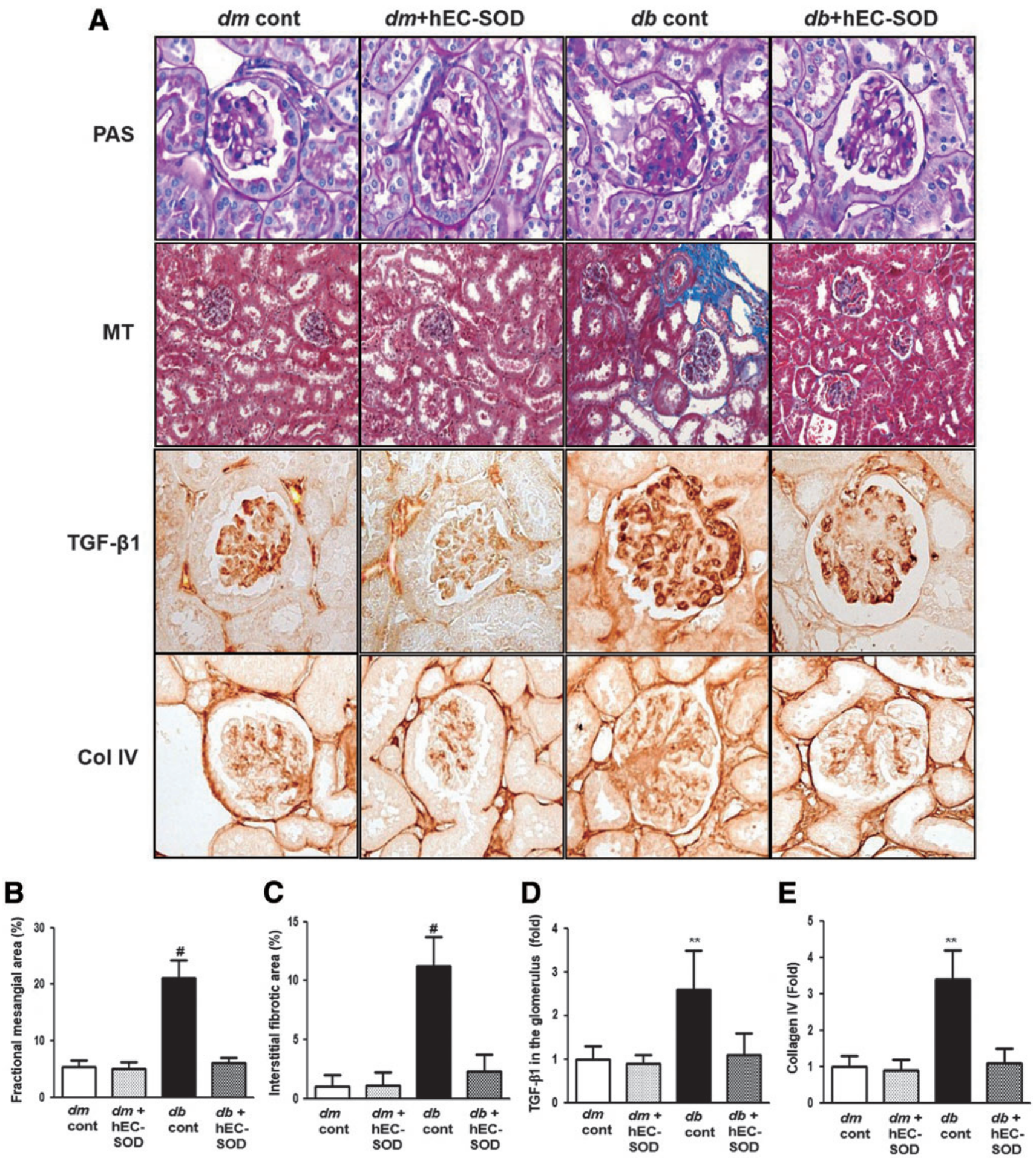

FIG. 1. Changes in glomerular phenotypes in $d b / m$ and $d b / d b$ mice with or without hEC-SOD treatment. Glomerular mesangial fractional area, tubulointerstitial fibrosis, and TGF- $\beta 1$ and type IV collagen expression in the glomerulus in the cortical area of $d b / m$ and $d b / d b$ mice with or without hEC-SOD treatment are shown. (A) Representative sections of periodic acid-Schiff stain, Masson's trichrome staining and representative immunohistochemical staining for TGF- $\beta 1$ and type IV collagen are shown (original magnification, $\times 400$ ). Quantitative analyses of the results for the (B) mesangial fractional area (\%), (C) interstitial fibrosis area (\%), (D) TGF- $\beta 1$ (fold), and (E) type IV collagen (fold) are shown. $* * p<0.01$ and ${ }^{\#} p<0.001 \mathrm{vs}$. $d b / m(d b / m$ cont $), d m$ cont $(d b / m$ cont $), d m+$ hEC-SOD $(d b / m$ hEC-SOD) and $d b+\mathrm{hEC}-\mathrm{SOD}$ ( $d b / d b$ hEC-SOD) mice. hEC-SOD, human recombinant extracellular superoxide dismutase; TGF- $\beta 1$, transforming growth factor- $\beta 1$. To see this illustration in color, the reader is referred to the web version of this article at www.liebertpub.com/ars 

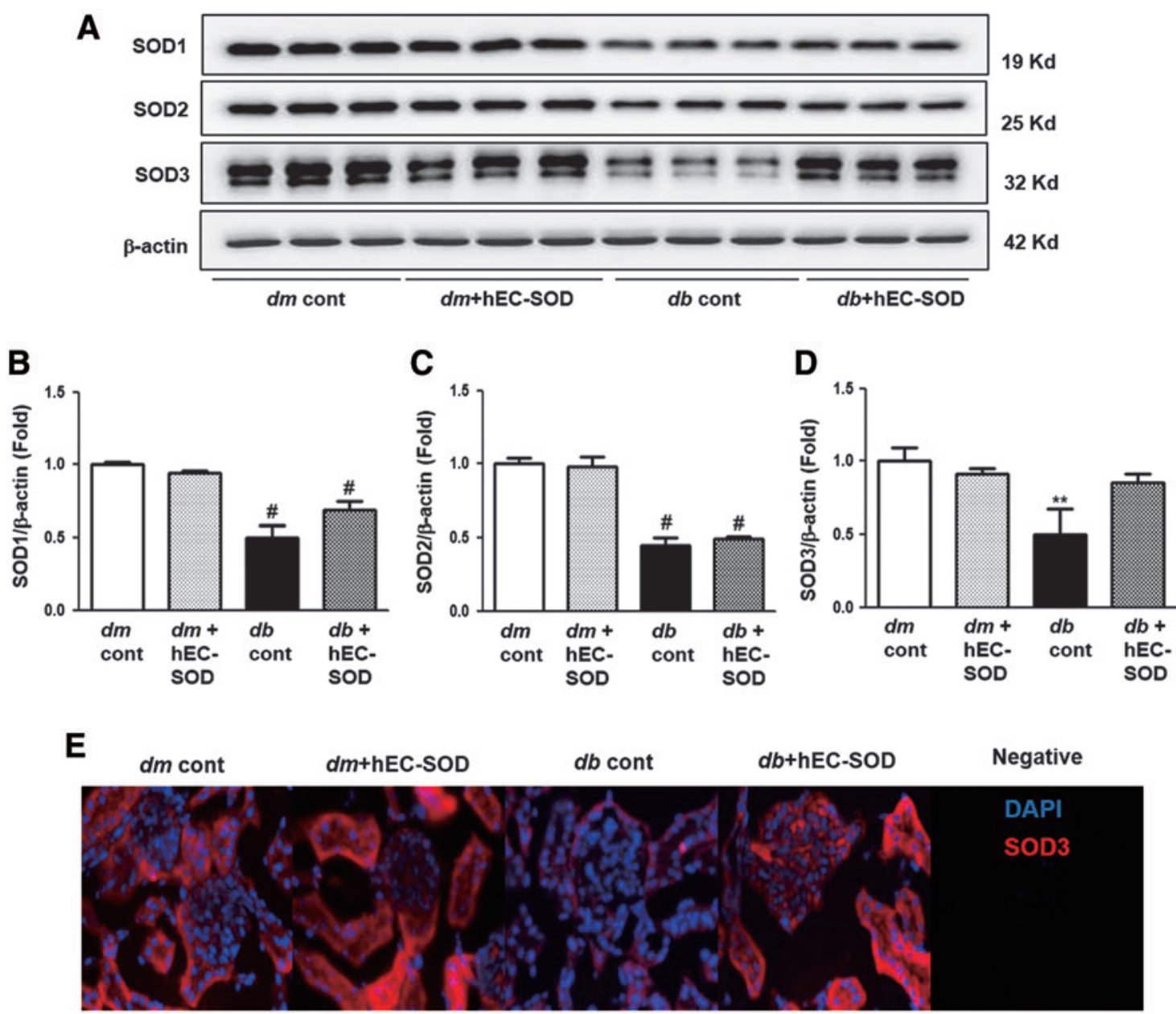

FIG. 2. Western blot analysis of the intrarenal SOD isoforms and immunofluorescence staining for SOD3 in $\mathrm{db} / \mathrm{m}$ and $\boldsymbol{d} \boldsymbol{b} / \boldsymbol{d} \boldsymbol{b}$ mice with or without $\mathbf{h E C}$-SOD treatment. Protein lysates $(30 \mu \mathrm{g})$ from renal cortex were separated by SDS-PAGE and analyzed by Western blotting. (A) Representative Western blot is shown for SOD1, SOD2, SOD3, and $\beta$-actin. Quantitative analyses are shown for (Supplementary Fig. S1; Supplementary Data are available online at www.liebertpub.com/ars). (B) SOD $1 / \beta$-actin and (C) SOD2/ $\beta$-actin, ${ }_{p}^{*}<0.001 v s . d m$ cont $(d b / m$ cont) and $d m+\mathrm{hEC}$-SOD $(d b / m$ hEC-SOD) mice. (D) SOD3/ $\beta$-actin. $* * p<0.01 v s$. $d m$ cont $(d b / m$ cont), $d m+$ hEC-SOD $(d b / m$ hEC-SOD) and $d b+\mathrm{hEC}-\mathrm{SOD}(d b / d b$ hEC-SOD) mice. (E) Representative immunofluorescence staining for SOD3 is shown in $d b / m$ and $d b / d b$ mice with or without hEC-SOD treatment. SDS-PAGE, sodium dodecyl sulfate-polyacrylamide gel electrophoresis. To see this illustration in color, the reader is referred to the web version of this article at www.liebertpub.com/ars

staining of 8-OH-dG also revealed the same result of higher expression in $d b / d b$ mice and reduced expression after treatment with hEC-SOD (Fig. $6 \mathrm{C}, p<0.01$ ). These findings suggest that oxidative stress in diabetic kidneys can be ameliorated by hEC-SOD treatment.

\section{Effects of EC-SOD on inflammatory cytokines and inflammatory cells}

Macrophages and monocytes are the major inflammatory cells found in diabetic kidneys and are broadly characterized by their activation state according to the M1/M2 classification. M1 macrophages express enhanced genes, which are proinflammatory and cytotoxic, inducible nitric oxide synthase (iNOS)/NO, interleukin (IL)-12, IL-8, tumor necrosis factor- $\alpha$ (TNF- $\alpha$ ), and monocyte chemoattractant protein-1 (MCP-1). In contrast, M2 macrophages generate antiinflammatory cytokines and substances involved in repairing function, arginase/ornithine, TGF- $\beta$, and mannose receptor.
In this study, serum MCP-1 and TNF- $\alpha$ levels were further increased in $d b / d b$ mice, and treatment with hEC-SOD in $d b / d b$ mice restored serum MCP- 1 and TNF- $\alpha$ to the levels of those from $d b / m$ and $d b / m$ hEC-SOD mice (Fig. 7A, B, $p<0.01$ and $p<0.01$, respectively). Tissue MCP-1 concentration was also increased in $d b / d b$ mice compared with $d b / m$ and $d b / m$ hEC-SOD mice (Fig. 7C, $p<0.001$ ). Administration of hEC-SOD attenuated tissue MCP-1 levels in $d b / d b$ hEC-SOD mice compared with that of $d b / d b$ mice $(p<0.05)$. As shown in Figure 7D, cell surface glycoprotein F4/80 (F4/ 80) staining in the glomerular area increased in $d b / d b$ mice and markedly reduced with hEC-SOD treatment. These findings suggest that inflammatory conditions caused by diabetes in $d b / d b$ mice can be improved by hEC-SOD treatment $(p<0.01)$. Expression of CD68 and granulocyte differentiation antigen-1 (Gr-1) was further increased in $d b / d b$ mice and reduced by hEC-SOD treatment (Fig. 7E-G, $p<0.01$ and $p<0.05$, respectively). Expression of arginase I did not change in $d b / d b$ mice and $d b / d b$ hEC-SOD mice, but 

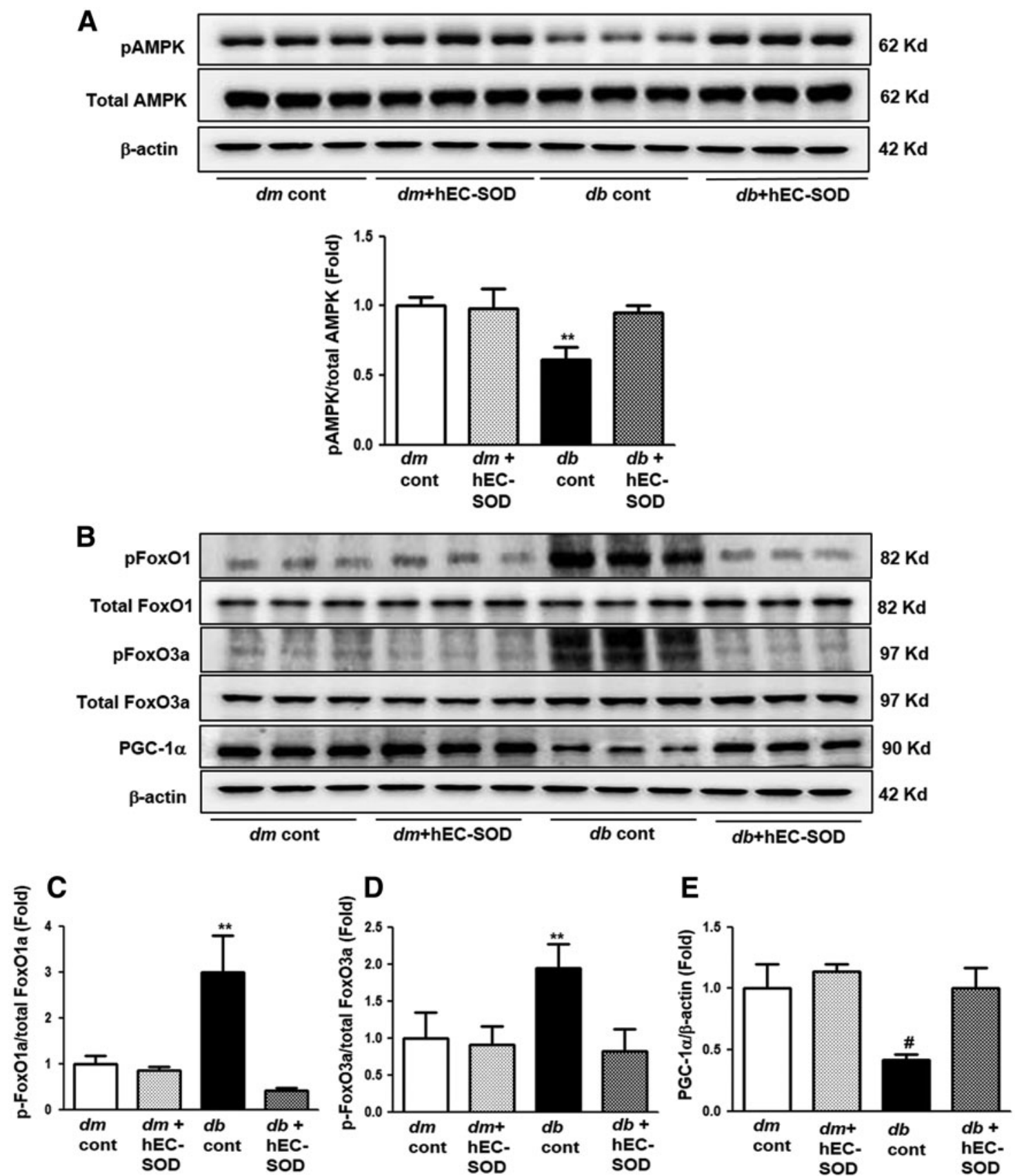

FIG. 3. Western blot analysis of phospho-Thr ${ }^{172}$ AMPK, total AMPK, phospho-Ser ${ }^{256}$ FoxO1, total FoxO1 phosphoSer $^{253}$ FoxO3a, total FoxO3a, and PGC- $1 \alpha$ in $d b / m$ and $d b / d b$ mice with or without hEC-SOD treatment. Protein lysates $(30 \mu \mathrm{g})$ from renal cortex were separated by SDS-PAGE and analyzed by Western blotting. (A) Representative Western blot and quantitative analyses are shown for phospho-Thr ${ }^{172}$ AMPK and total AMPK (Supplementary Fig. S1). (B) Representative Western blot is shown for phospho-Ser ${ }^{256}$ FoxO1, total FoxO1 phospho-Ser ${ }^{253}$ FoxO3a, total FoxO3a, PGC-1 $\alpha$, and $\beta$-actin. Quantitative analyses of the results from the Western blot: (Supplementary Fig. S1). (C) phospho-Ser ${ }^{256}$ FoxO1/total FoxO1, (D) phospho-Ser ${ }^{253}$ FoxO3a/total FoxO3a, (E) PGC-1 $\alpha / \beta$-actin. $* * p<0.01$ and ${ }^{\#} p<0.001 v s$. $d m$ cont $(d b / m$ cont), $d m+$ hEC-SOD $(d b / m$ hEC-SOD) and $d b+\mathrm{hEC}-\mathrm{SOD}(d b / d b$ hEC-SOD) mice. AMPK, adenosine monophosphate-activated protein kinase; FoxO, forkhead box $\mathrm{O}$ transcription factor; PGC- $1 \alpha$ peroxisome proliferative-activated receptor $\gamma$ coactivator $1 \alpha$.

FIG. 4. Western blot analysis of nuclear Nrf2, cytoplasmic/total Nrf2, Keap1, NQO-1, HO-1, and NADPH oxidases in $\boldsymbol{d} \boldsymbol{b} / \boldsymbol{m}$ and $\boldsymbol{d b} / \boldsymbol{d} \boldsymbol{b}$ mice with or without $\mathbf{h E C}-S O D$ treatment. Protein lysates $(30 \mu \mathrm{g})$ from renal cortex were separated by SDSPAGE and analyzed by Western blotting. (A) Representative Western blot showing nuclear Nrf2, cytoplasmic/total Nrf2, Keap1, NQO-1, HO-1, lamin B1, and $\beta$-actin. Quantitative analyses of the results from the Western blot: (Supplementary Fig. S2). (B) nuclear Nrf2/lamin B1, (C) cytoplasmic Nrf2/total Nrf2, (D) Keap1/ $\beta$-actin, (E) NQO-1/ $\beta$-actin, and (F) HO-1/ $\beta$-actin. $* p<0.05$ and $* * p<0.01 v s$. $d m$ cont $(d b / m$ cont $), d m+\mathrm{hEC}-\mathrm{SOD}(d b / m$ hEC-SOD) and $d b+\mathrm{hEC}-\mathrm{SOD}(d b / d b \mathrm{hEC}-\mathrm{SOD}) \mathrm{mice}$. (G) Representative Western blot showing Nox1, Nox2, Nox4, and $\beta$-actin. Quantitative analyses of the results from the Western blot: (Supplementary Fig. S2). (H) Nox1/ $\beta$-actin, (I) Nox $2 / \beta$-actin, and (J) Nox $4 / \beta$-actin, ${ }^{* *} p<0.01$, and ${ }^{\#} p<0.001 v s$. $d m$ cont ( $d b / m$ cont $), d m+$ hEC-SOD ( $d b / m$ hEC-SOD) and $d b+\mathrm{hEC}-\mathrm{SOD}(d b / d b$ hEC-SOD) mice. HO-1, heme oxygenase; Keap1, Kelchlike ECh-associated protein 1; NQO-1, NAD(P)H dehydrogenase 1; Nrf2, nuclear factor E2-related factor 2. 


\section{A}
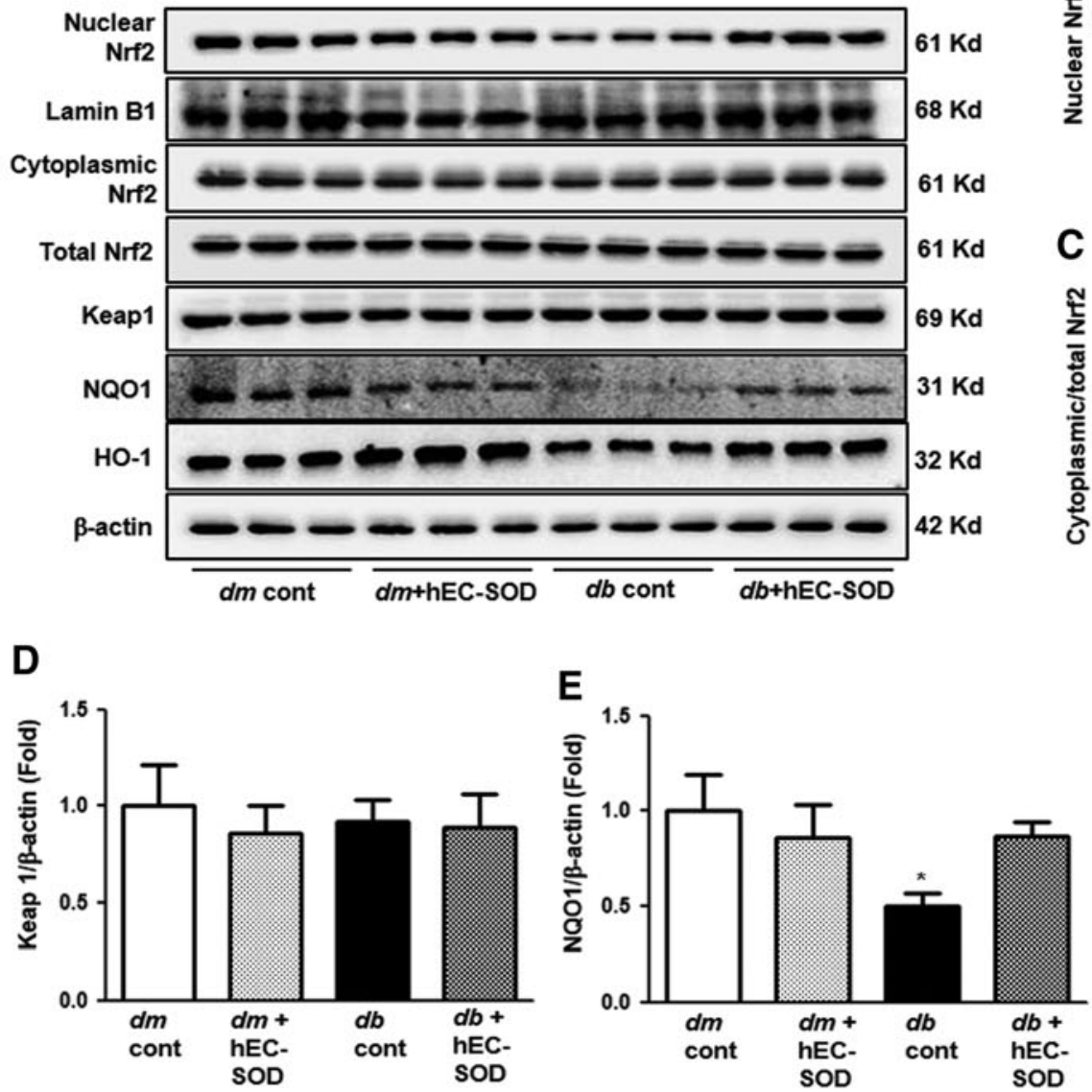

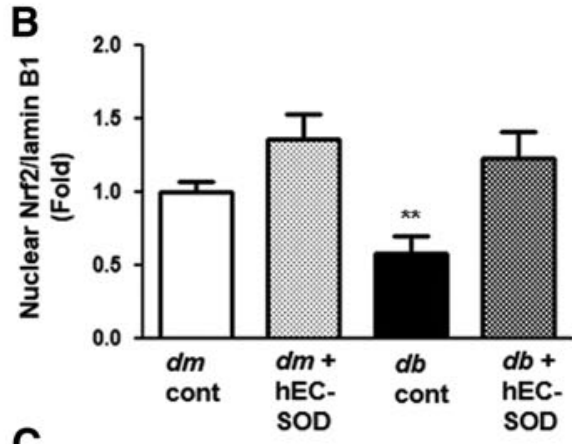

C

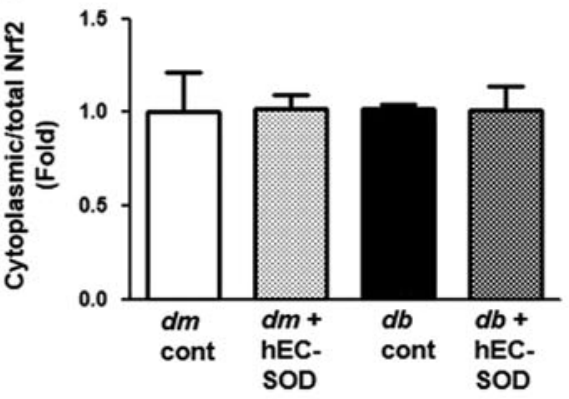

F

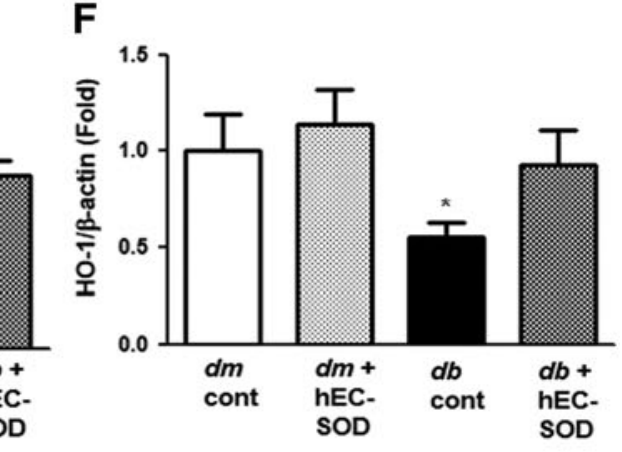

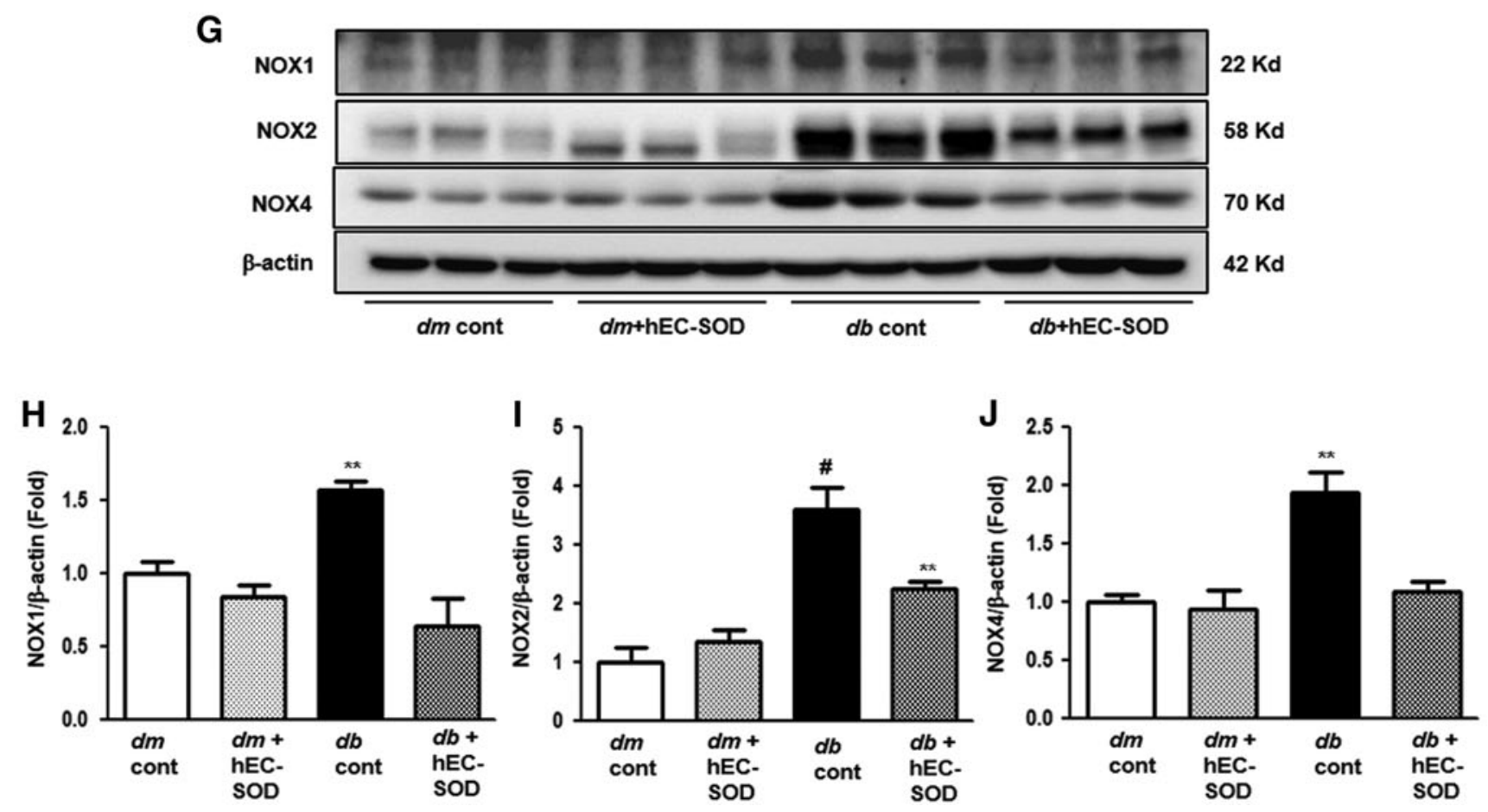

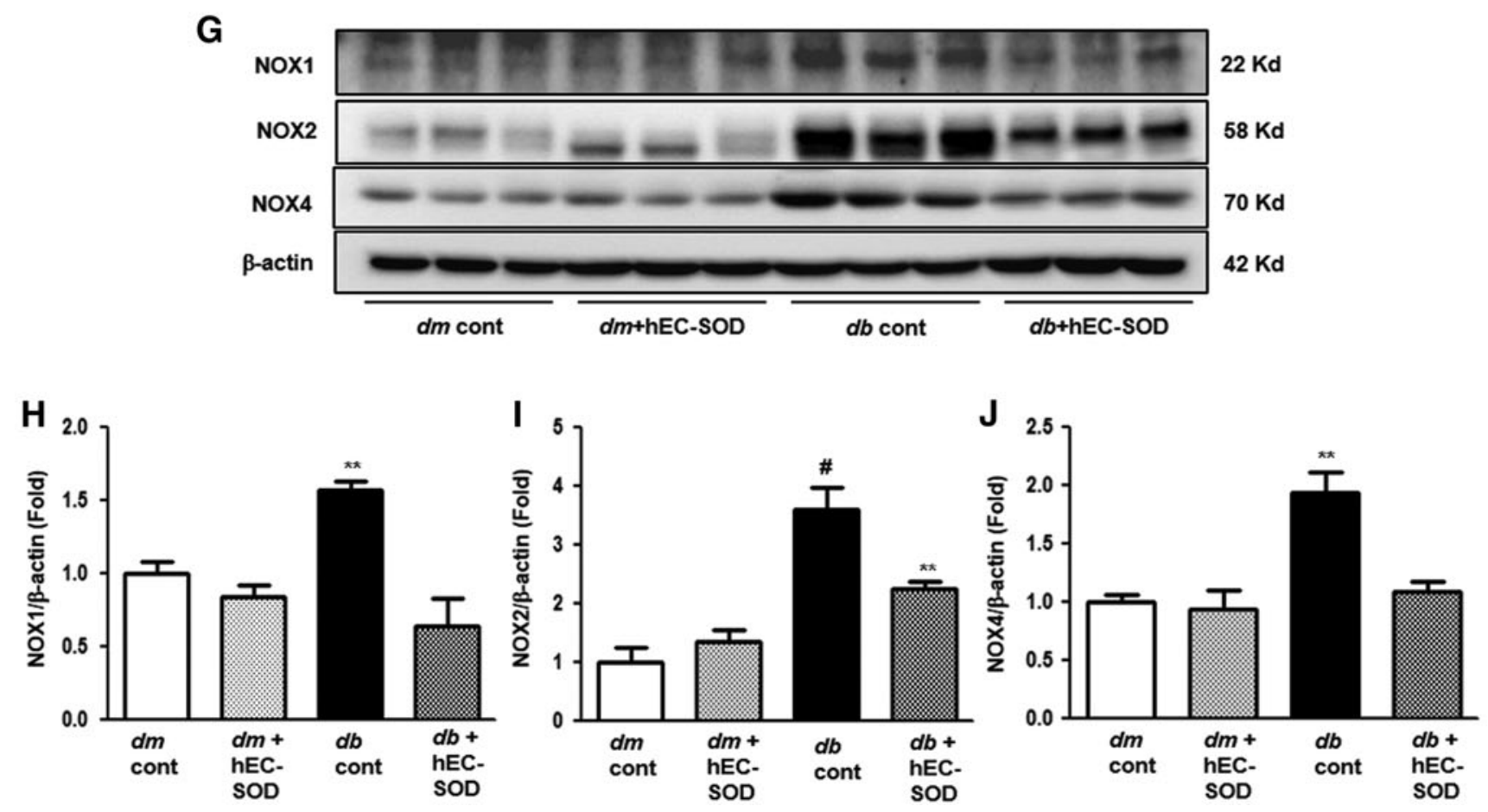


A
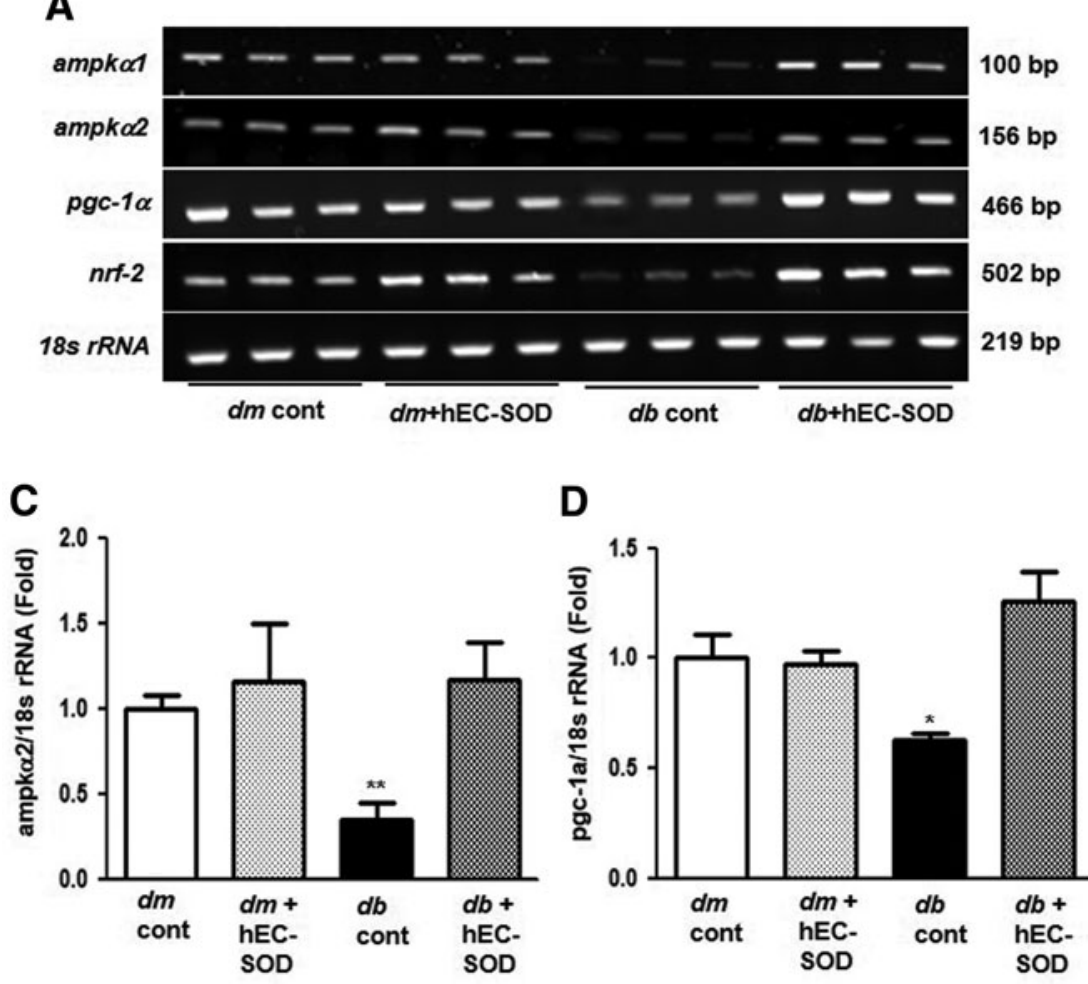

D

$\mathbf{F}$

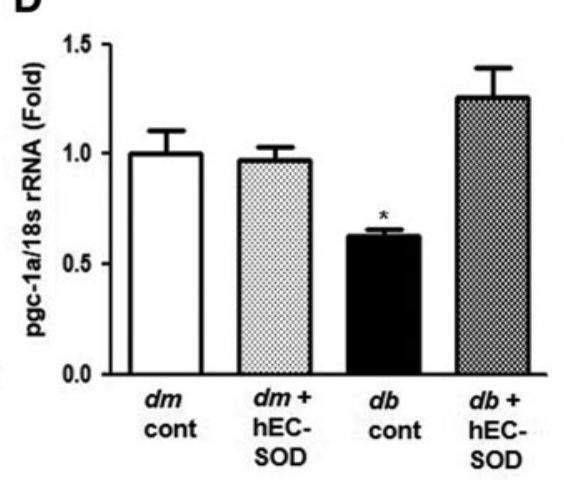

B

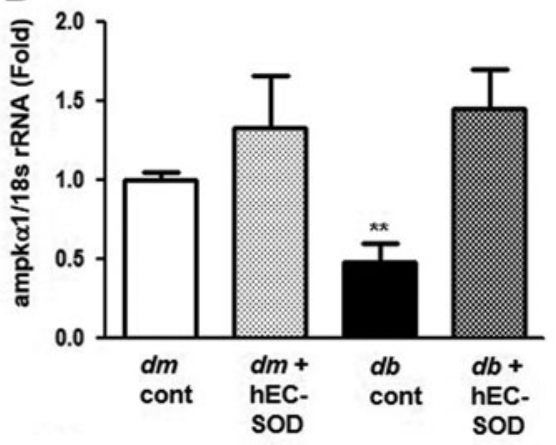

E

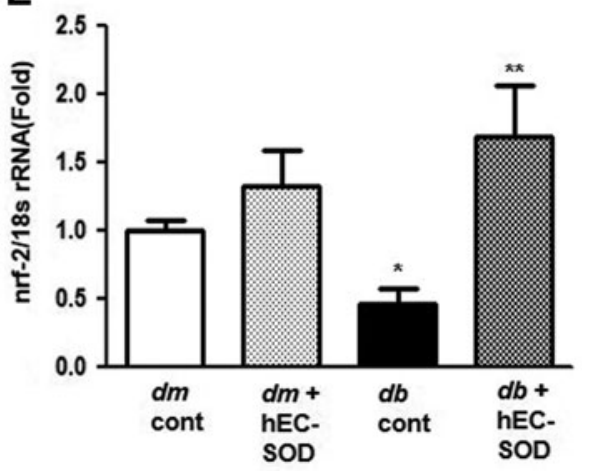

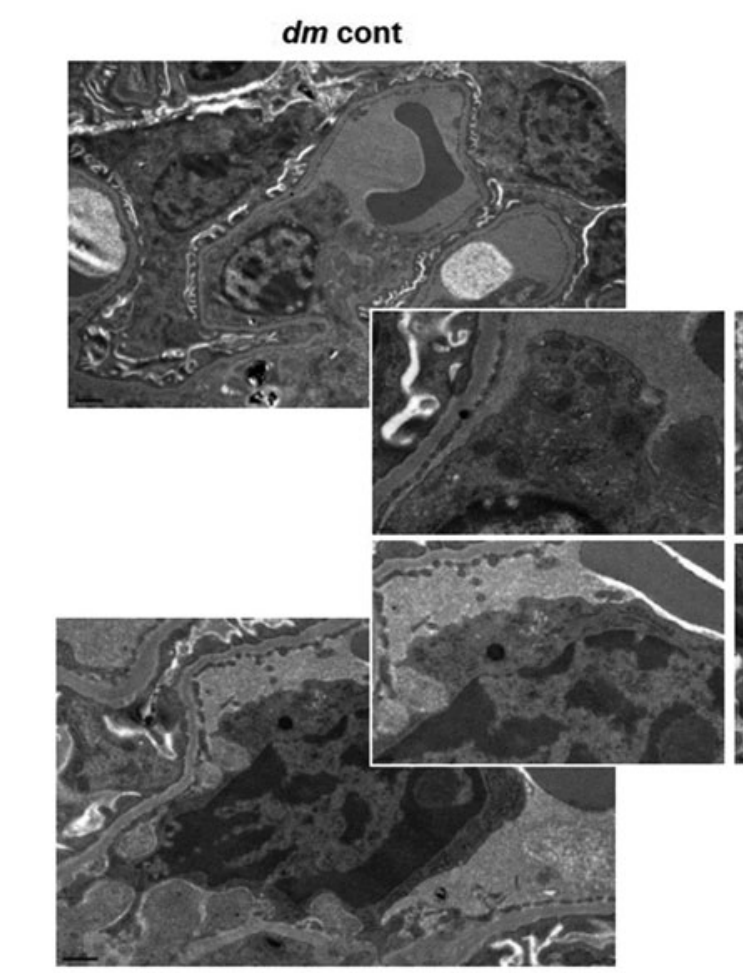

db cont

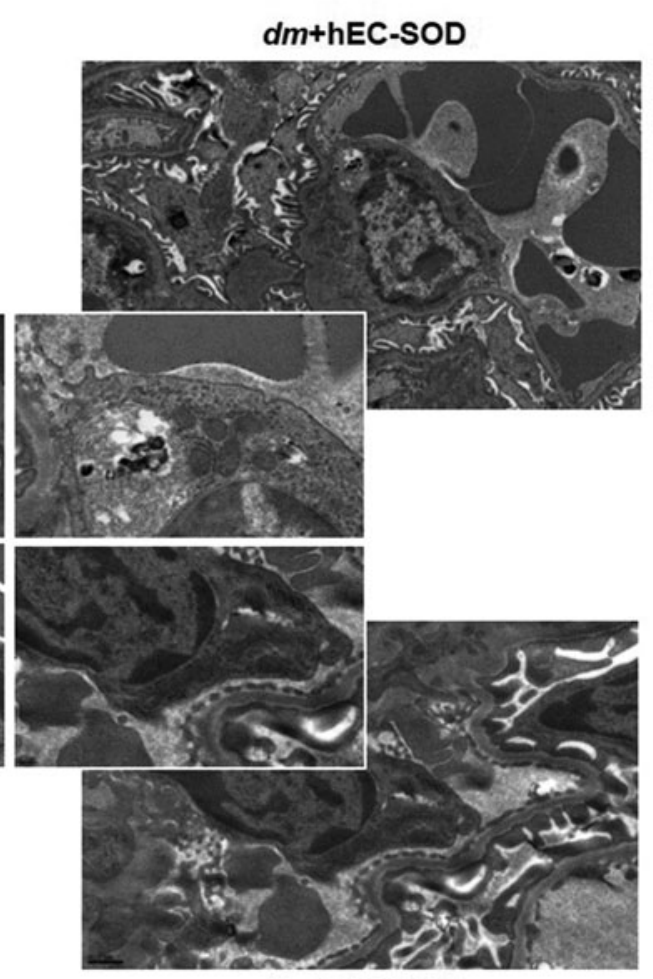

$d b+h E C-S O D$

FIG. 5. RT-PCR of AMPK, PGC-1 $\alpha$, and Nrf2 and electron micrographs showing mitochondrial morphology in $d b /$ $\boldsymbol{m}$ and $\boldsymbol{d} \boldsymbol{b} / \boldsymbol{d} \boldsymbol{b}$ mice with or without hEC-SOD treatment. (A) Representative RT-PCR showing ampk $\alpha 1$, ampk $\alpha 2$, pgc-1 $\alpha$, $n r f 2$, and $18 s r R N A$. Quantitative analyses of the results from the RT-PCR: (Supplementary Fig. S3). (B) ampk $\alpha 1 / 18 s r R N A$, (C) $a m p k \alpha 2 / 18 s r R N A$, (D) $p g c-1 \alpha / 18 s r R N A$, and (E) $n r f 2 / 18 s \quad r R N A . * P<0.05$ and $* * P<0.01$ compared with other groups. (F) Representative images of mitochondrial morphology by transmission electron microscopy in kidney tissues of $d b / m$ and $d b / d b$ mice with or without hEC-SOD treatment. RT-PCR, reverse transcription polymerase chain reaction. 
FIG. 6. The changes of oxidative stress markers in $d b / m$ and $d b / d b$ mice with or without hEC-SOD treatment. The 24-h urinary 8-OH-dG and 8-isoprostane concentrations of the study mice are shown. (A) 24-h urinary $8-\mathrm{OH}-\mathrm{dG}$ concentrations, (B) 24-h urinary 8isoprostane concentrations, (C) representative immunohistochemical staining for $8-\mathrm{OH}-\mathrm{dG}$ is shown (original magnification, $\times 400)$. **p $<$ 0.01 and ${ }^{\#} p<0.001$ vs. $d m$ cont $(d b / m$ cont $), d m+$ hECSOD $(d b / m$ hEC-SOD) and $d b+\mathrm{hEC}-\mathrm{SOD} \quad(d b / d b$ hECSOD) mice and $* p<0.05 v s$. $d b / d b$ mice. 8-OH-dG, 8-hydroxy-2'-deoxyguanosine. To see this illustration in color, the reader is referred to the web version of this article at www.liebertpub.com/ars
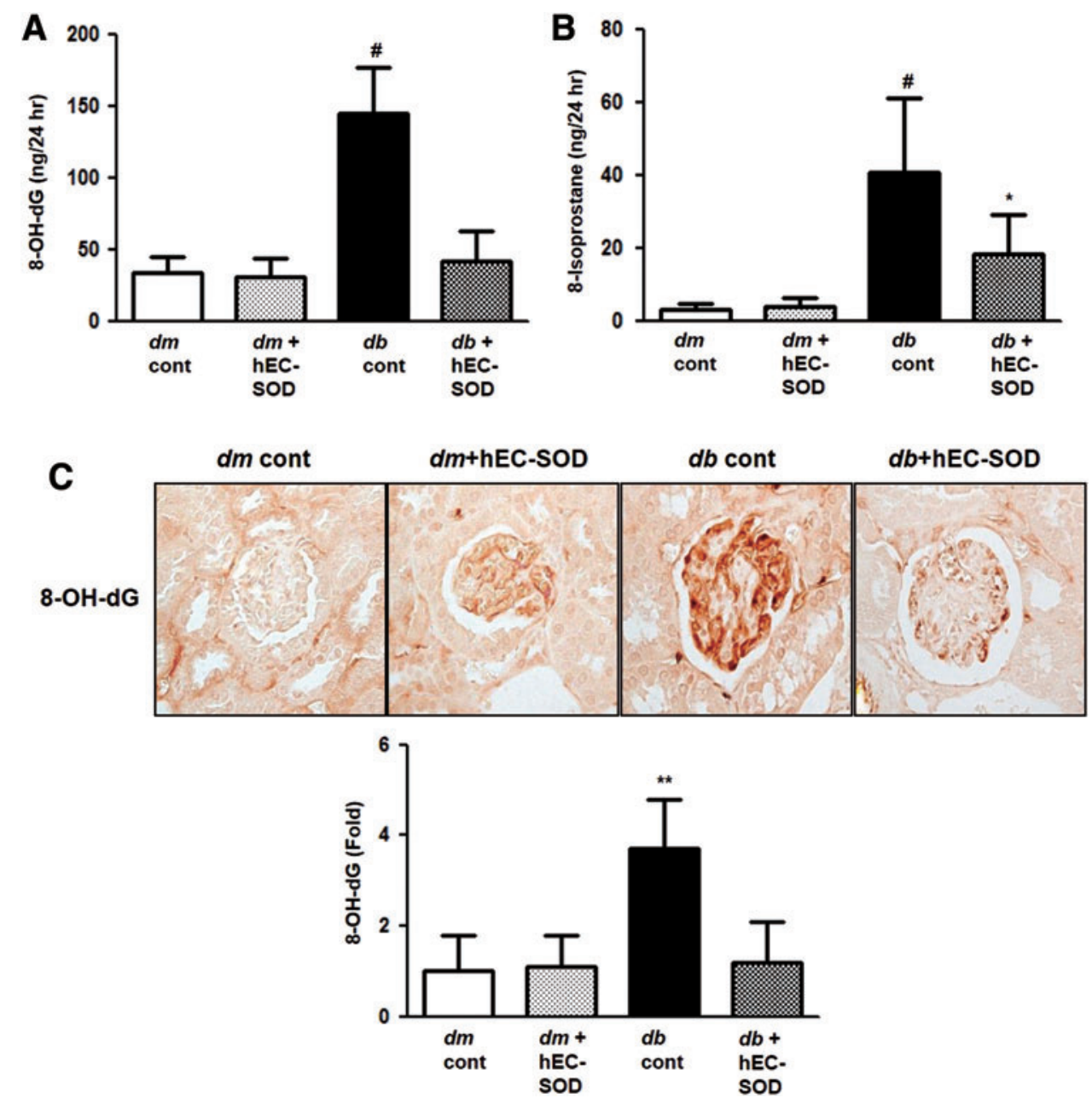

expression of arginase II was markedly enhanced in $d b / d b$ mice and reduced in $d b / d b$ hEC-SOD mice (Fig. 7E, H, I, $p<0.05$ and $p<0.01$, respectively). Expression of iNOS was significantly increased in $d b / d b$ mice and significantly decreased by hEC-SOD treatment (Fig. 7E, J, $p<0.01$ ). Consequently, these results demonstrate that EC-SOD improves renal inflammation in DN through reducing proinflammatory cytokines produced from macrophage M1 polarization without the changes of macrophage M2 polarization.

\section{Renal expression of BCL-2, BAX, and terminal deoxynucleotidyl transferase-mediated dUTP nick end-labeling-positive cells}

To evaluate the antiapoptotic effects of hEC-SOD treatment, terminal deoxynucleotidyl transferase-mediated dUTP nick end-labeling (TUNEL)-positive cells in the glomeruli from all experimental groups were counted. The number of TUNEL-positive cells in $d b / d b$ mice was significantly attenuated by hEC-SOD treatment (Fig. $8 \mathrm{~A}, p<0.001$ ). The antiapoptotic B cell leukemia/lymphoma 2 (BCL-2) protein level decreased and the proapoptotic BCL-2-associated X (BAX) protein level increased in $d b / d b$ mice. As a result, BCL-2/BAX ratio was suppressed in $d b / d b$ mice. The administration of hEC-SOD in $d b / d b$ mice enhanced BCL-2 protein and attenuated $\mathrm{BAX}$ protein, resulting in a normalized BCL-2/BAX ratio (Fig. 8B, $p<0.01$ ).

\section{In vitro studies}

The effects of hEC-SOD treatment on high glucose (HG)induced inflammation, oxidative stress, and apoptosis related to AMPK activation and downstream molecules were evaluated in cultured human glomerular endothelial cells (HGECs). HG induced marked decreases in the activation of SOD isoforms and phosphor-Thr ${ }^{172} /$ total AMPK (Fig. 9A-E, $p<0.05, p<0.05, p<0.05$ and $p<0.01$, respectively). hECSOD treatment in HG-treated HGECs did not influence the levels of intracellular SOD isoforms in a dose-dependent manner. In contrast, EC-SOD restored expression of phospho-Thr ${ }^{172}$ AMPK in HG-treated HGECs (Fig. 9A, E). Administration of hEC-SOD to the low-glucose (LG) group did not affect SOD isoforms or phosphor-Thr ${ }^{172} /$ total AMPK in cultured HGECs. Consistent with the results of an in vivo study, $\mathrm{HG}$ enhanced phospho-Ser ${ }^{256} /$ total FoxO1 and phospho-Ser ${ }^{253} /$ total FoxO3a and inhibited PGC- $1 \alpha$. hEC-SOD treatment in HG medium recovered the expression of phospho-FoxOs and PGC- $1 \alpha$, but these changes were not associated with treatment dose of hEC-SOD (Fig. 9F-I, $p<0.01, p<0.01$ and $p<0.01$, respectively). 

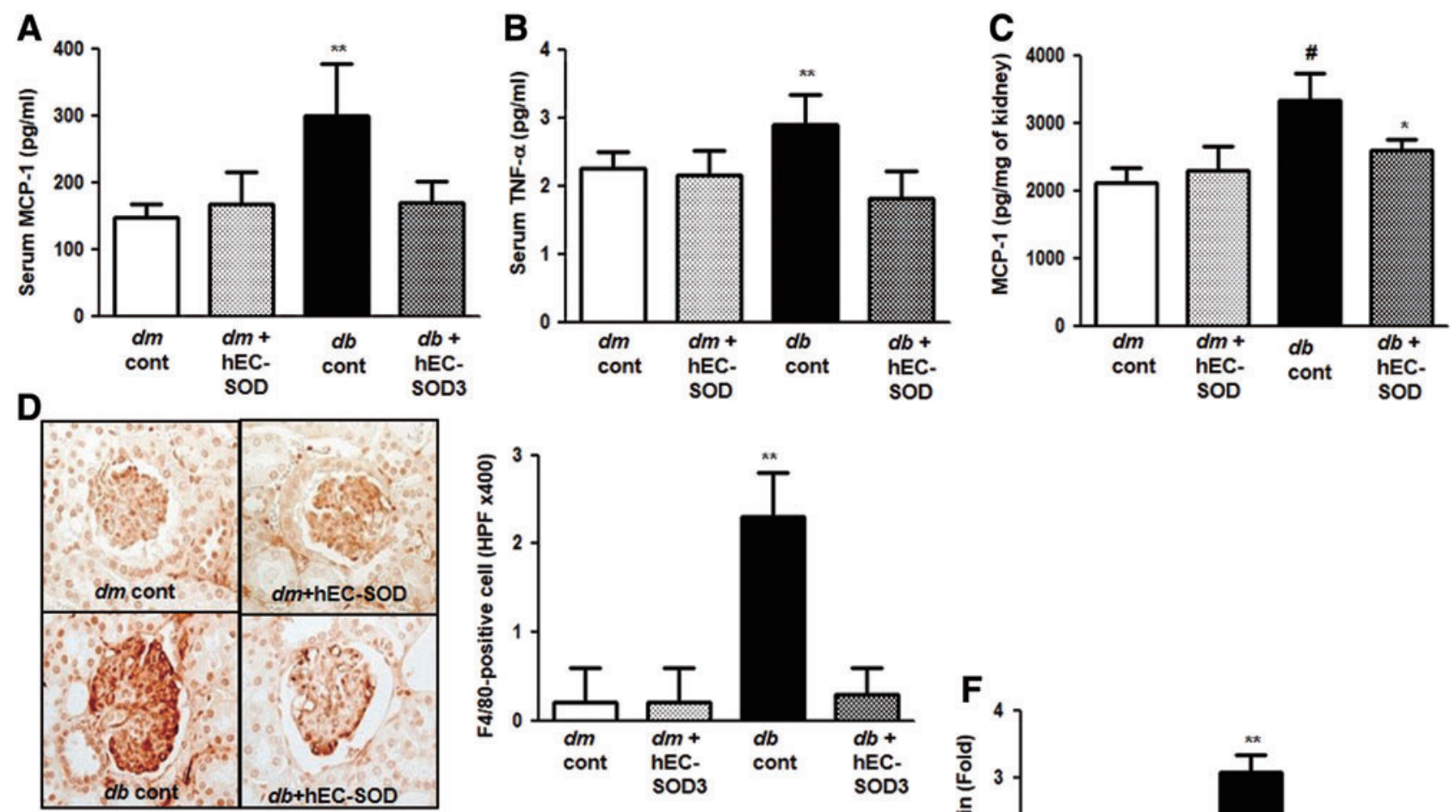

E
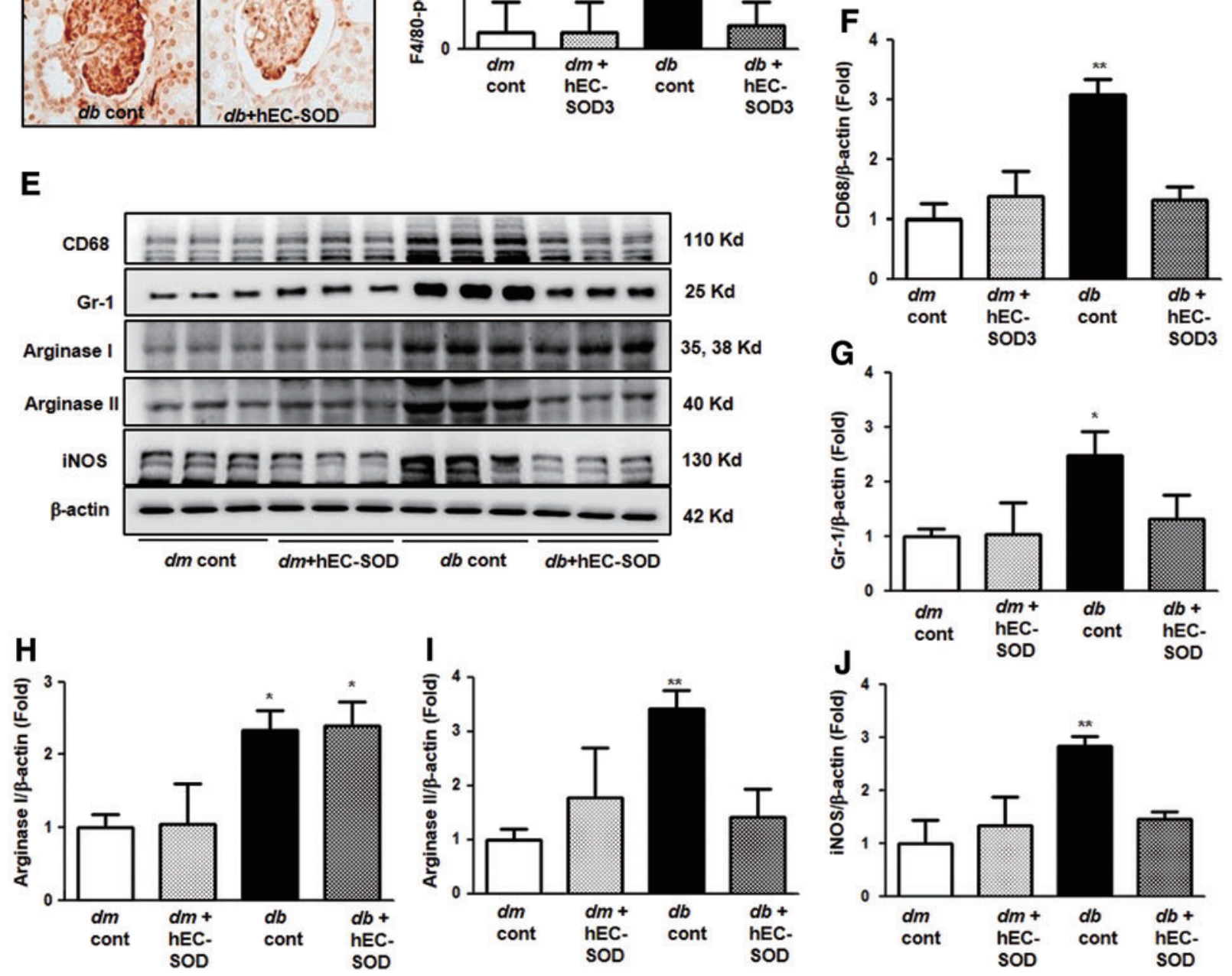

FIG. 7. The changes of inflammatory markers in $d b / m$ and $d b / d b$ mice with or without hEC-SOD treatment. The serum or tissue MCP-1 and TNF- $\alpha$ concentration of the study mice are shown. (A) Serum MCP-1 concentration. (B) Serum TNF- $\alpha$ concentration. (C) Renal MCP-1 concentration, ${ }^{*} p<0.01$ and ${ }^{*} p<0.001 v s$. $d m$ cont $(d b / m$ cont), $d m+\mathrm{hEC}-\mathrm{SOD}(d b / m \mathrm{hEC}-\mathrm{SOD})$ and $d b+\mathrm{hEC}$-SOD ( $d b / d b$ hEC-SOD) mice and $* p<0.05 v s$. $d b$ cont ( $d b / d b$ cont) mice. (D) Representative images and quantitative analyses of the results for the F4/80-positive cells (fold) are shown. $* * p<0.01 v s$. $d m$ cont $(d b / m$ cont), $d m+\mathrm{hEC}$-SOD ( $d b / m \mathrm{hEC}$ SOD) and $d b+\mathrm{hEC}-\mathrm{SOD}(d b / d b \mathrm{hEC}-\mathrm{SOD})$ mice. (E) Representative Western blot showing CD68, Gr-1, arginase I/II, iNOS, and $\beta$ actin. Quantitative analyses of the results from the Western blot: (Supplementary Fig. S3). (F) CD68/ $\beta$-actin, (G) Gr-1/ $\beta$-actin, (H) arginase $\mathrm{I} / \beta$-actin, (I) arginase II $/ \beta$-actin, and (J) iNOS/ $\beta$-actin. $* p<0.05$, $* * p<0.01 v s$. $d m$ cont $(d b / m$ cont $), d m+\mathrm{hEC}$-SOD $(d b /$ $m$ hEC-SOD) and $d b+\mathrm{hEC}-\mathrm{SOD}(d b / d b$ hEC-SOD) mice. F4/80, cell surface glycoprotein F4/80; Gr-1, granulocyte-differentiation antigen-1; iNOS, inducible nitric oxide synthase; MCP-1, monocyte chemoattractant protein-1; TNF- $\alpha$, tumor necrosis factor- $\alpha$. To see this illustration in color, the reader is referred to the web version of this article at www.liebertpub.com/ars 
FIG. 8. The changes of apoptosis markers in $\mathrm{db} / \mathrm{m}$ and $d b / d b$ mice with or without hEC-SOD treatment. (A) Representative immunohistochemical staining for TUNEL-positive cells and the quantitative analyses of the results are shown. ${ }^{\#} p<0.001 \mathrm{vs}$. $\mathrm{dm}$ cont $(\mathrm{db} / \mathrm{m}$ cont $), d m+$ hEC-SOD $(d b / m$ hEC-SOD) and $d b+\mathrm{hEC}$ SOD $(d b / d b \quad$ hEC-SOD $)$ mice. (B) Representative Western blot of the BAX, BCL-2, and $\beta$-actin levels and quantitative analyses of the results of the BCL-2/ $\mathrm{BAX}$ ratio are shown. (Supplementary Fig. S4). $* * p<0.01 v s$. dm cont $(d b / m$ cont $), d m+$ hEC-SOD $(d b / m$ hEC-SOD) and $d b+\mathrm{hEC}-$ SOD $(d b / d b \quad$ hEC-SOD $)$ mice. To see this illustration in color, the reader is referred to the web version of this article at www.liebertpub .com/ars
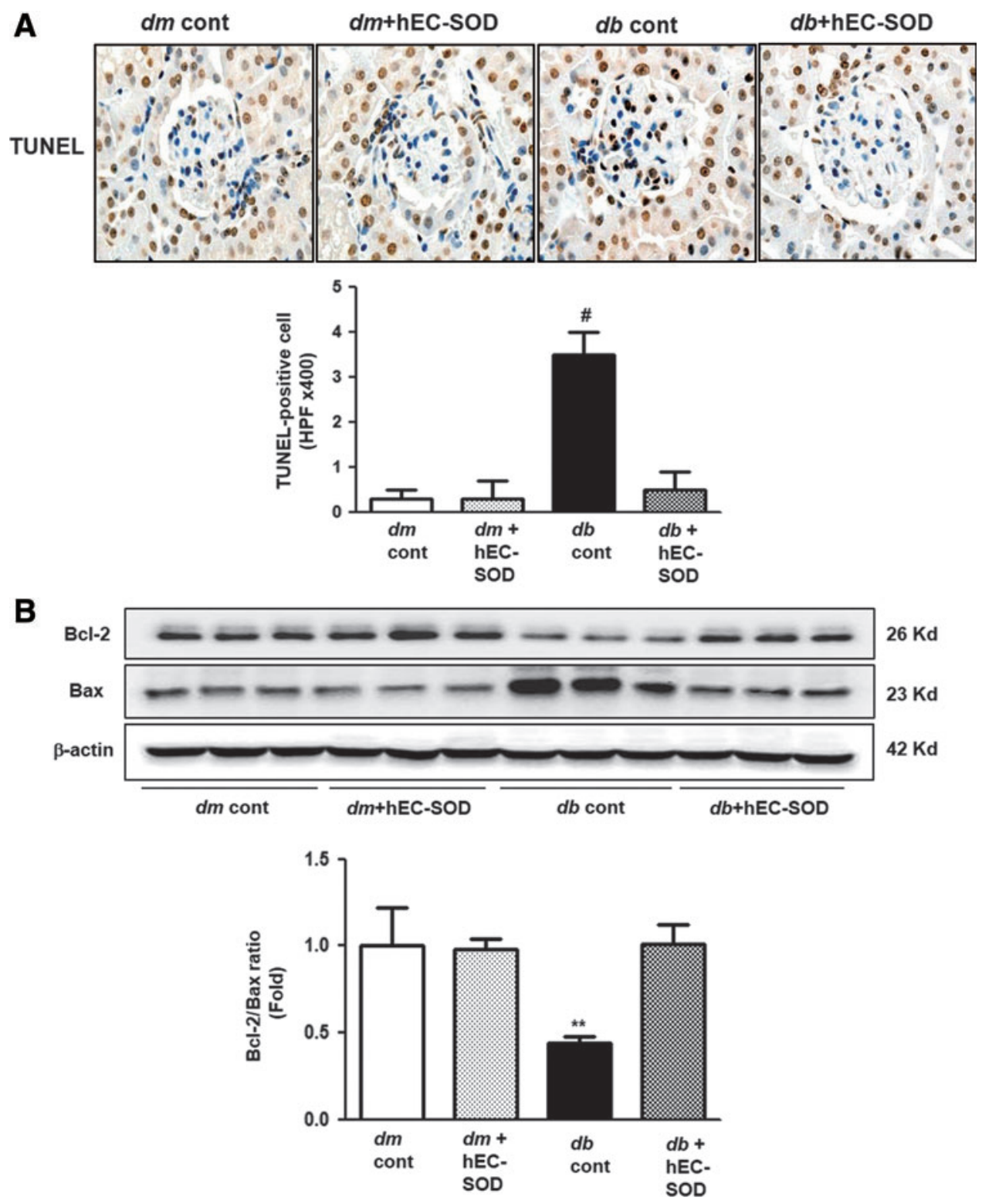

To investigate whether AMPK activation was related to stimulation by hEC-SOD treatment, additional experiments were conducted using small interfering RNAs (siRNAs) for $A M P K \alpha 1$ and $A M P K \alpha 2$ in cultured HGECs. Expression of phosphor-Thr ${ }^{172}$ and total AMPK was significantly suppressed in cultured HGECs transfected with siRNAs for $A M P K \alpha 1$ and $A M P K \alpha 2$ (Fig. 10A-C, $p<0.01$ and $p<0.01$, respectively). Consistent with changes in AMPK expression, the expression of PGC- $1 \alpha$ also markedly reduced in cultured HGECs transfected with siRNAs for AMPK $\alpha 1$ and $A M P K \alpha 2$ (Fig. 10A, D, $p<0.01$ ). The transfected siRNAs for $A M P K \alpha 1$ and $A M P K \alpha 2$ in HG-treated HGECs consistently suppressed AMPK activation despite hEC-SOD treatment $(0.1 \mathrm{U} / \mathrm{mL})$ compared with the siRNA control group (Fig. 11A, B, $p<0.01$ ). Expression of FoxO1, FoxO3a, and PGC- $1 \alpha$, downstream targets of AMPK, was also inhibited in HGECs treated with HG medium transfected with siRNAs for $A M P K \alpha 1$ and $A M P K \alpha 2$ (Fig. 11A, C-E, $p<0.01$, $p<0.01$ and $p<0.01$, respectively).

\section{Discussion}

This study demonstrated that EC-SOD downregulation is associated with increased oxidative stress and decreased AMPK expression in diabetic kidneys. These changes lead to the inactivation of PGC- $1 \alpha-\mathrm{Nrf} 2$ and FoxOs signaling, which subsequently results in increased inflammation and apoptosis. Conversely, hEC-SOD treatment ameliorates DN by activating AMPK and PGC- $1 \alpha-\mathrm{Nrf} 2$ and dephosphorylating FoxOs, which reverses apoptotic renal injury and inflammation.

Oxidative stress has been implicated as a critical pathogenic factor in the pathogenesis of DN $(10,24)$. Previously, EC-SOD has shown protective effects in other animal models 

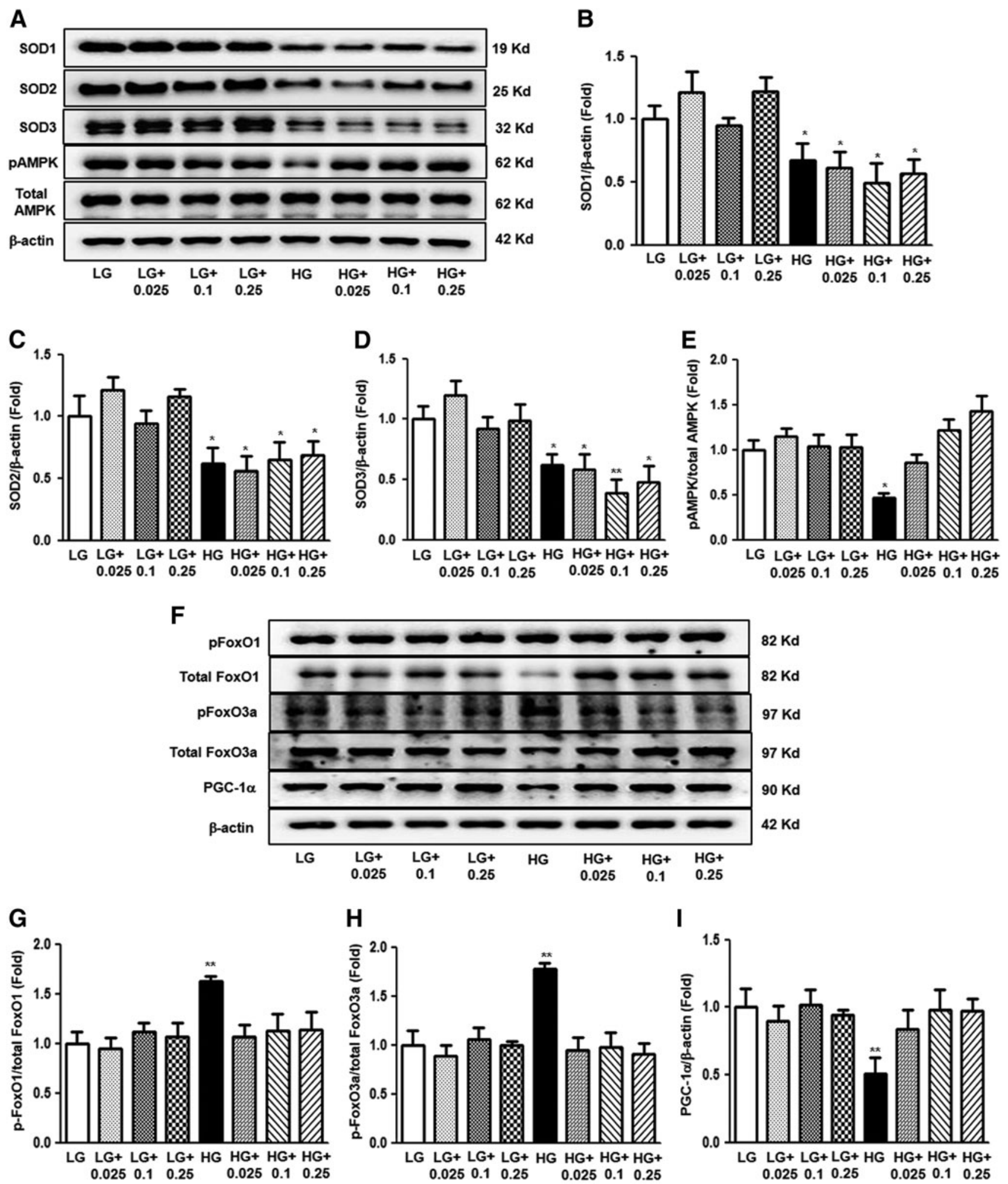

FIG. 9. The effect of dose-dependent hEC-SOD treatment on SOD isoforms and AMPK, FoxOs family, and PGC$1 \alpha$ expression in the cultured glomerular endothelial cells treated with LG or HG medium. SOD1, SOD2, SOD3, phospho-Thr ${ }^{172}$ AMPK, total AMPK, phospho-Ser ${ }^{256}$ FoxO1, total FoxO1, phospho-Ser ${ }^{253}$ FoxO3a, total FoxO3a, and PGC$1 \alpha$ levels were assessed in the cultured glomerular endothelial cells treated with LG or HG medium. Protein lysates $(10 \mu \mathrm{g})$ were separated by SDS-PAGE and analyzed by Western blotting. (A) Representative Western blot of SOD1, SOD2, SOD3, phospho-Thr ${ }^{172}$ AMPK, and total AMPK is shown. Quantitative analyses of SOD1, SOD2, SOD3, phospho-Thr ${ }^{172}$ AMPK, total AMPK, and $\beta$-actin levels are shown; (Supplementary Fig. S4). (B) SOD1/ $\beta$-actin, (C) SOD2/ $\beta$-actin, (D) SOD3/ $\beta$-actin, and (E) phospho-Thr ${ }^{172}$ AMPK/total AMPK. ${ }^{*} p<0.05$ and ${ }^{* *} p<0.01$ compared with LG. (F) Representative immunoblot analysis of phospho-Ser ${ }^{256}$ FoxO1, total FoxO1, phospho-Ser ${ }^{253}$ FoxO3a, total FoxO3a, and PGC-1 $\alpha$ in the cultured glomerular endothelial cells and the quantitative analyses of the results (Supplementary Fig. S4). (G) Phospho-Ser ${ }^{256}$ FoxO1/total FoxO1, (H) phospho-Ser ${ }^{253}$ FoxO3a/total FoxO3a, and (I) PGC-1 $\alpha / \beta$-actin, ${ }^{* *} p<0.01$ compared with other groups. HG, high glucose; LG, low glucose. 

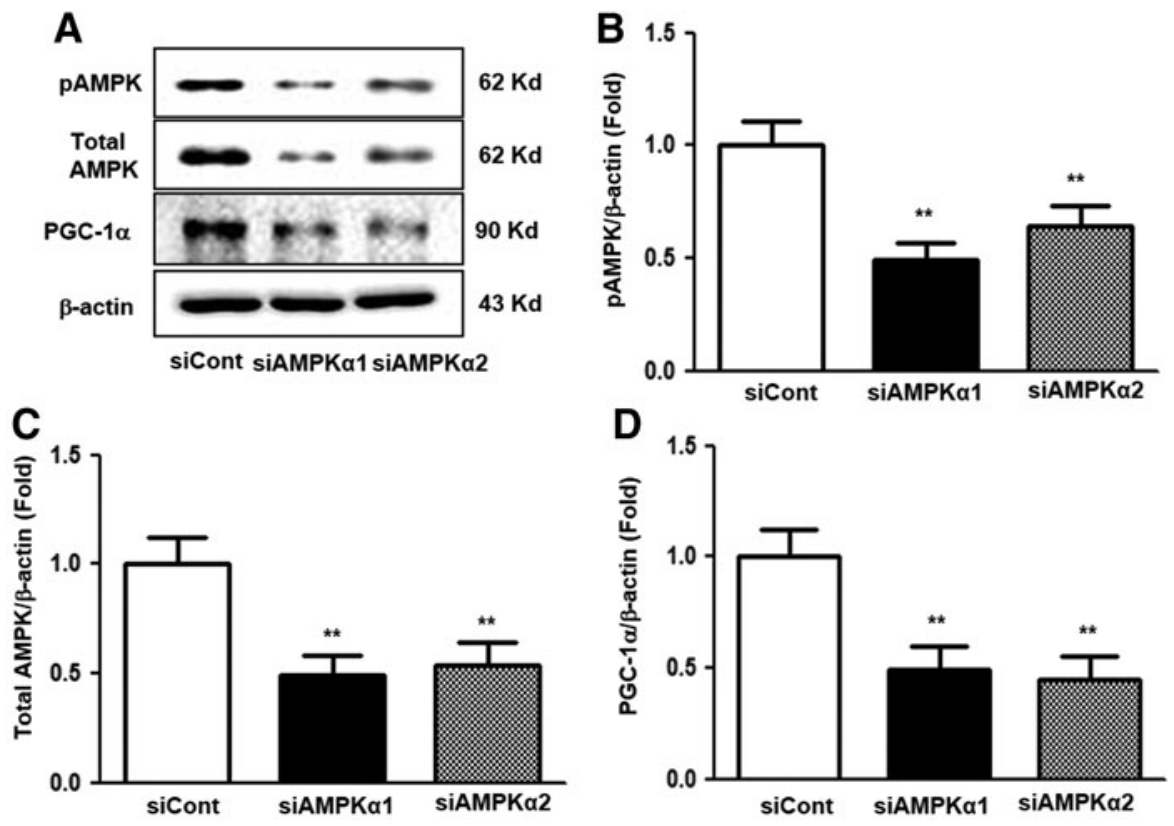

FIG. 10. The effect of $A M P K \alpha 1$ or $A M P K \alpha 2$ siRNA on AMPK and PGC-1 $\alpha$ expression in the cultured glomerular endothelial cells. The cultured glomerular endothelial cells are transfected with $50 \mathrm{nmol} / \mathrm{L} \mathrm{control}$ siRNA or $50 \mathrm{nmol} / \mathrm{L}$ $A M P K \propto 1$ or $A M P K \propto 2$ siRNA using transfection reagent. Approximately $24 \mathrm{~h}$ after transfection, the levels of phospho$\mathrm{Thr}^{172}$ AMPK, total AMPK, and PGC- $1 \alpha$ signaling in the cultured glomerular endothelial cells. Protein lysates (10 $\left.\mu \mathrm{g}\right)$ from the cultured glomerular endothelial cells were separated by SDS-PAGE and analyzed by Western blotting. (A) Representative Western blot analysis of phospho-Thr ${ }^{172}$ AMPK, total AMPK, PGC- $1 \alpha$, and $\beta$-actin levels, and the quantitative analyses of the results are also shown: (B) phospho-Thr ${ }^{172}$ AMPK/ $\beta$-actin, (C) total AMPK/ $\beta$-actin, (D) PGC- $1 \alpha / \beta$-actin. $* * p<0.01$ compared with siCont. siRNA, small interfering ribonucleic acid.

of kidney injury, such as renal ischemia reperfusion injury or adriamycin-induced nephropathy $(34,45)$. However, evidence regarding the role of EC-SOD in DN has been inconsistent to date. Kimura et al. showed that decreased serum EC-SOD level in patients with type 2 diabetes was associated with increased proteinuria and severity of DN (28). In in vivo studies, renal expression of EC-SOD was significantly suppressed in a mouse model of type 1 DN (13). However, another study showed that only SOD1 deficiency alone, but not SOD3 deficiency, resulted in pronounced proteinuria and oxidative stress in C57BL/6-Akita diabetic mice. Therefore, they suggested that EC-SOD might not be a major factor involved in the pathogenesis of DN (14). In contrast, a recent study demonstrated that hEC-SOD treatment protects against $\mathrm{DN}$, resulting in increased antioxidant activity through downregulation of the ROS/ERK1/2 signaling pathway (31). Another study showed that the activation of EC-SOD by the combination of angiotensin AT1 receptor blocker and peroxisome proliferator-activated receptor $\gamma$ agonist attenuated glomerular sclerosis, macrophage infiltration, and reversed vascular endothelial dysfunction in an animal model of type 2 diabetic kidney (15). The inconsistency of experimental approaches among animal studies might be responsible for the discrepant results. This study demonstrated that renal ECSOD expression measured by Western blot and immunohistochemical staining was significantly decreased in diabetic kidneys. In addition, hEC-SOD administration decreased $24 \mathrm{~h}$ albuminuria and histological changes, such as mesangial expansion and interstitial fibrosis, by decreased oxidative stress through activation of SOD3 in diabetic mice.
AMPK plays a principal role in cell growth and cellular energy homeostasis and is a key component of the development of DN (27). Dugan et al. (7) demonstrated that hyperglycemia suppressed the generation of mitochondrial superoxide, leading to reduced mitochondrial biogenesis by downregulating expression of PGC- $1 \alpha$ due to inactivated AMPK. However, the exact mechanisms of AMPK and ECSOD activation have yet to be identified. This study confirmed that AMPK is directly activated by hEC-SOD treatment in diabetic mice. Knockdown of $A M P K \alpha 1$ and $A M P K \propto 2$ blocks the induction of AMPK and its downstream targets, such as PGC- $1 \alpha$ and FoxOs, by hEC-SOD treatment in HGECs cultured with HG medium. We evaluated mitochondrial dysfunction by TEM, and our study confirmed that AMPK activation by hEC-SOD treatment in diabetic mice improved hyperglycemia-induced mitochondrial ROS production through the enhancement of the AMPK-PGC- $1 \alpha$ pathway consistent with a previous study (7). AMPK activation also attempts to suppress oxidative injury by suppressing Nox-derived ROS and mitochondria dysfunction in diabetic kidney disease (42). In this study, the expression levels of Nox 1 , Nox 2 , and Nox 4 , which are representative isoforms associated with the pathogenesis of DN, were inhibited by EC-SOD-induced AMPK activation in diabetic kidney. These results suggest that EC-SOD directly suppresses oxidative stress through AMPK activation, but the antioxidant effect of AMPK activation was not limited to increased mitochondrial biogenesis. AMPK may act not only as a master energy sensor but also as a "master ROS sensor" of the cell (4). 

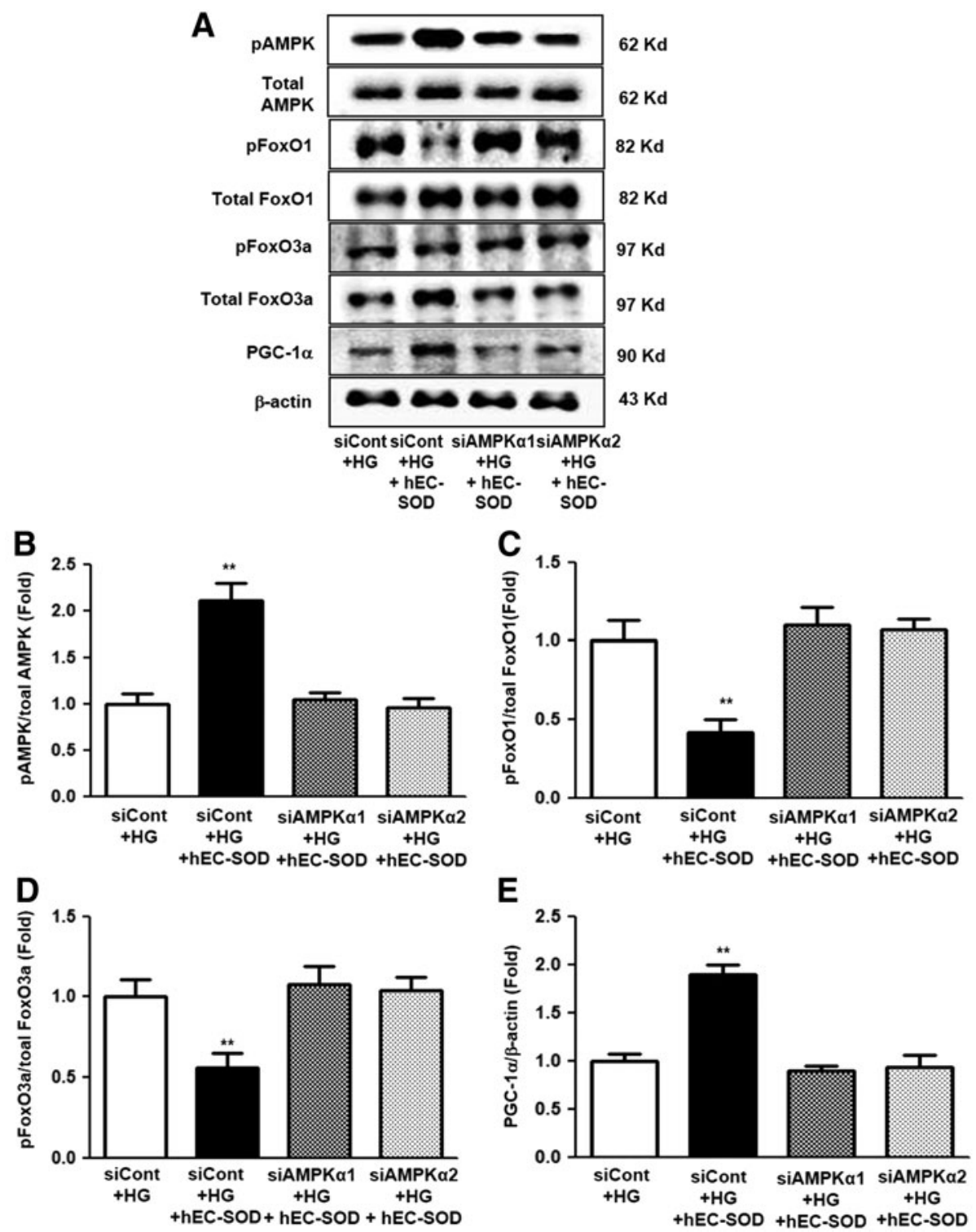

FIG. 11. The effect of $A M P$ $K \alpha 1$ or $A M P K \alpha 2$, siRNA in a HG environment with hECSOD treatment. The cultured glomerular endothelial cells were transfected with $50 \mathrm{n} M$ control SiRNA or $50 \mathrm{n} M A M P K \alpha 1$ or $A M P K \alpha 2$ siRNA using transfection reagent and stimulated with hEC-SOD treatment $(0.1 \mathrm{U} / \mathrm{mL})$ in HG medium. Approximately $24 \mathrm{~h}$ after transfection, the levels of phospho-Thr ${ }^{172}$ AMPK, total AMPK, phospho-Ser ${ }^{256}$ FoxO1, total FoxO1, phospho-Ser ${ }^{253}$ FoxO3a, total FoxO3a, and PGC$1 \alpha$ signaling in the $\mathrm{HG}$ medium stimulated with hEC-SOD were analyzed. Protein lysates $(10 \mu \mathrm{g})$ from the cultured glomerular endothelial cells were separated by SDS-PAGE and analyzed by Western blotting. (A) Representative Western blot of phospho-Thr ${ }^{172}$ AMPK, total AMPK, phospho$\mathrm{Ser}^{256}$ FoxO1, total FoxO1, phospho-Ser ${ }^{253}$ FoxO3a, total FoxO3a, PGC- $1 \alpha$, and $\beta$-actin levels, and the quantitative analyses of the results are also shown: (B) phospho$\mathrm{Thr}^{172}$ AMPK/total AMPK, (C) phospho-Ser $256 /$ total FoxO1, (D) phospho-Ser ${ }^{253} /$ total FoxO3a, and (E) PGC- $1 \alpha / \beta$-actin. **p $p 0.01$ compared with other groups.
Our study also demonstrated that EC-SOD suppressed oxidative stress in DN through the AMPK-PGC- $1 \alpha-\mathrm{Nrf} 2$ signaling pathway. The exact mechanisms of AMPKmediated antioxidative responses remain unclear, but recent studies showed that AMPK stimulates the Nrf2 signaling pathway $(35,37)$. In addition, PGC- $1 \alpha$ can promote transcription of antioxidant enzymes in response to oxidative stress $(1,43)$. Although a molecular interaction between Nrf2 and PGC- $1 \alpha$ has not been identified, upregulation of PGC- $1 \alpha$ coactivates Nrf2 expression and stimulates upregulation of antioxidant genes, such as HO-1, NQO-1, and SODs $(1,39)$. In this study, nuclear translocation of Nrf2 was significantly suppressed in diabetic mice and HGECs cultured with HG medium. hEC-SOD treatment also upregulated HO-1 and NQO-1 expression through nuclear translocation of Nrf2, leading to attenuated elevation of the markers of oxidative stress in diabetic mice. These changes were substantially associated with the AMPK-PGC- $1 \alpha$ signaling pathway. We used $A M P K \alpha 1$ and $A M P K \alpha 2$ siRNA to elucidate the effect of
EC-SOD on the AMPK-PGC- $1 \alpha$ pathway. PGC- $1 \alpha$ activation induced by hEC-SOD treatment was abolished by $A M P K \alpha 1$ and $A M P K \alpha 2$ siRNA treatment in HG-treated HGECs. Therefore, we suggest that the protective role of hEC-SOD is mediated through direct activation of AMPK, which, in turn, increases expression of PGC- $1 \alpha$.

The adaptive response of the AMPK-FoxO3a signaling pathway is also involved in upregulating antioxidant enzymes against oxidative stress (17). In previous studies, the phenolic compound reduced intracellular ROS levels by increasing catalase through the AMPK-FoxO3a pathway, and $A M P K$ siRNA suppressed FoxO3a upregulation in vascular endothelial cells (48). EC-SOD also promoted cell survival through phosphorylation of FoxO3a and antiapoptotic mir-21 upregulation and proapoptotic bim mRNA downregulation in a skeletal muscle ischemia model (34). In our study, expression of AMPK and FoxOs was inactivated in diabetic mice and HG-treated HGECs. In addition, hEC-SOD treatment restored activated AMPK and decreased phosphorylation of FoxO1 and 
FoxO3a. EC-SOD activation ameliorated hyperglycemiainduced apoptotic renal cell death, which resulted in an increased BCL-2/BAX ratio in diabetic mice. We also demonstrated through an in vitro study using $A M P K$ knockdown HGECs that hEC-SOD-induced FoxOs expression is completely dependent on AMPK activation. hEC-SOD-induced FoxO1 and FoxO3a dephosphorylation was diminished by $A M P K \alpha 1$ and $A M P K \alpha 2$ siRNA treatment in HGECs treated with HG medium. Our data suggest that targeting the AMPKFoxOs signaling pathway through EC-SOD activation could be beneficial to alleviate intracellular oxidative stress and apoptosis in diabetic kidney injury. To our knowledge, this is the first demonstration of the protective role of hEC-SOD through activation of AMPK and its downstream targets in in vitro and in vivo models of $\mathrm{DN}$.

Hyperglycemia-induced ROS production stimulates recruitment of numerous inflammatory cells and production of inflammatory cytokines implicated in the pathogenesis of DN (22). The inflammatory cytokines involved in the development of DN might contribute to the progression of renal injury either directly or indirectly $(3,19)$. Among these cytokines and chemokines, MCP- 1 and TNF- $\alpha$ are central to the pathogenesis of inflammatory damage in DN $(3,46)$. The Nrf2-Keap1 system also plays an important role in reducing inflammation in DN $(2,47)$. Recent studies demonstrated that EC-SOD modulates innate and adaptive immune responses, ameliorating the progression of skin and airway inflammation $(33,36)$. In this study, increased levels of circulating MCP-1 and TNF- $\alpha$ and renal expression of MCP-1 were suppressed by hEC-SOD treatment. We also demonstrated that increased levels of CD68, Gr-1, arginase II, and iNOS in $d b / d b$ mice were inhibited by hEC-SOD treatment. These results suggest that hEC-SOD has not only antioxidant effects but also local and systemic anti-inflammatory effects in DN.

In conclusion, our study demonstrated that treatment with hEC-SOD repairs intrarenal oxidative stress, apoptosis, and inflammation caused by diabetes to prevent and improve DN. The renoprotective effects of hEC-SOD were associated with activated AMPK-PGC- $1 \alpha$ and subsequently increased Nrf2 expression in diabetic kidneys. hEC-SOD treatment also inhibited phosphorylation of FoxO3a and FoxO1, resulting in prevention of renal oxidative stress, inflammation, and apoptotic cell death. These results suggest that hEC-SOD is a potential therapeutic target for treatment of type $2 \mathrm{DN}$ through intrarenal AMPK-PGC- $1 \alpha-\mathrm{Nrf} 2$ and AMPK-FoxOs signaling.

\section{Materials and Methods}

\section{Preparation of recombinant EC-SOD}

The hEC-SOD was prepared as described previously (32). In brief, 293 cells were transient transfected with SOD3 construct for $48 \mathrm{~h}$. The supernatant was collected and purified using a column containing Ni-NTA agarose (Qiagen, Valencia, CA), followed by dialysis. The purified SOD3 activity was measured with an SOD assay kit (Dojindo, Sunnyvale, $\mathrm{CA})$. For injection into the mice or treatment in vitro, SOD3 was filtered to eliminate endotoxin.

\section{Animals and treatment}

Eight-week-old male C57BLKS/J $d b / m$ and $d b / d b$ mice, purchased from Jackson Laboratories (Bar Harbor, ME), were divided into four groups and received a regular diet of chow. hEC-SOD $(3500 \mathrm{U} /(\mathrm{kg} \cdot$ day $), 120 \mu \mathrm{L})$ was intraperitoneally injected in $d b / d b$ mice $(n=8)$ and age- and gendermatched $d b / m$ mice $(n=8)$ once a week for 8 weeks. Control $d b / d b$ mice $(n=6)$ and $d b / m$ mice were $(n=6)$ intraperitoneally injected the same dose of saline during the experimental period. At week 16, all animals were anesthetized by intraperitoneal injection of a mixture of Rompun ${ }^{\circledR} 10 \mathrm{mg} / \mathrm{kg}$ (Bayer Korea, Ansan, Gyeonggi-Do, Korea) and Zoletil ${ }^{\circledR}$ $30 \mathrm{mg} / \mathrm{kg}$ (Virbac, Carros, France) and sacrificed. The kidneys were rapidly dissected and stored in $10 \%$ buffered formalin. All experiments were conducted using the renal cortex. Blood samples were collected from the left ventricle of mice, and plasma was stored at $-70^{\circ} \mathrm{C}$. This experimental protocol was approved by the Animal Care Committee of The Catholic University of Korea, and performed in accordance with institutional animal care guidelines.

\section{Blood and urine parameters}

All of the blood samples from animals were obtained after an overnight fasting. Fasting blood glucose was determined by an Accu-check meter (Roche Diagnostics, St Louis, MO). HbA1c was measured from red cell lysates using high performance liquid chromatography (HPLC) (Bio-Rad, Richmond, CA). A 24-h urine collection was performed using metabolic cages at 16 weeks. Urinary albumin concentration was assessed by immunoassay (Bayer, Elkhart, IN), and plasma and urinary creatinine concentrations were measured by HPLC (Beckman Instruments, Fullerton, CA).

\section{Light microscopy study}

Histology was assessed after periodic acid-Schiff (PAS) staining and Masson's trichrome staining. Each glomerular cross-section using PAS-stained sections was used to assess fractional mesangial area, and each glomerular cross-section using Masson's trichrome-stained sections was used to assess interstitial fibrotic area. More than 30 glomeruli per kidney were counted, and the average was used for analysis.

\section{Immunohistochemical \\ and immunofluorescence staining}

We examined immunohistochemistry for TGF- $\beta 1$, Col IV, F4/80, and 8-OH-dG. Four-micrometer-thick sections were incubated overnight with anti-TGF- $\beta 1$ (1:100; R\&D Systems, Minneapolis, MN, Product No. MAB240), anti-COL IV (1:200; Bodesign International, Saco, ME, Product No. T40263R), anti-F4/80 (1:200; Serotek, Oxford, United Kingdom, Product No. MCA497), and 8-OH-dG (1:200; JICA, Shizuoka, Japan, Product No. MOG-020P) in a humidified chamber at $4^{\circ} \mathrm{C}$. The antibodies were detected with a peroxidase-conjugated secondary antibody and using the Vector Impress Kit (Vector Laboratories, Burlingame, CA) and a 3,3-diaminobenzidine substrate solution with nickel chloride enhancement. The sections were then dehydrated in ethanol, cleared in xylene, and mounted without counterstaining. All sections were assessed in a blinded manner using light microscopy (Olympus BX-50; Olympus Optical, Tokyo, Japan). The number of positive cells was assessed per high power field, and at least 20 fields were reviewed for each slide. We detected apoptotic cells by TUNEL assay using the 
ApopTag In Situ Apoptosis Detection Kit (ChemiconMillipore, Billerica, MA, Product No. S7101).

For immunofluorescence staining, kidney sections were incubated with anti-SOD3 antibody (Santa Cruz Biotechnology, Inc., CA, Product No. sc-67089) overnight and then observed with antirabbit Alexa Fluor-555 (Life Technologies, OR). The images were captured by confocal microscopy (LSM5 Live Configuration Variotwo VRGB; Zeiss, Germany).

\section{Transmission electron microscopic analysis}

For TEM, kidney specimens were fixed in $4 \%$ paraformaldehyde and $2.5 \%$ glutaraldehyde in $0.1 \mathrm{M}$ phosphate buffer overnight at $4^{\circ} \mathrm{C}$. After washing in $0.1 \mathrm{M}$ phosphate buffer, the specimens were postfixed with $1 \%$ osmium tetroxide in the same buffer for $1 \mathrm{~h}$. The specimens were then dehydrated using a series of graded ethanol, exchanged through acetone, and embedded in Epon 812. Ultrathin sections $(70-80 \mathrm{~nm})$ were obtained by ultramicrotome (Leica Ultracut UCT; Leica, Germany) and were double stained with uranyl acetate and lead citrate and examined in a transmission electron microscope (JEM 1010, Tokyo, Japan) at $60 \mathrm{kV}$.

\section{Enzyme-linked immunosorbent assay to assess oxidative stress and inflammation markers}

To evaluate oxidative stress, 24-h urinary 8-OH-dG (OXIS Health Products, Inc., Portland, OR, Product No. 2106) and 8-isoprostane (Oxis Research, Foster City, CA) levels were measured. To evaluate inflammatory markers, serum samples were analyzed using a mouse Magnetic Luminex Screening assay containing a premixed multianalyte kit for murine TNF- $\alpha$ and MCP-1 (R\&D Systems, Product No. LXSAMSM) on a Luminex 200 (Austin, TX) according to the manufacturer's instructions. Secretory level of MCP-1 in kidney tissue lysate was determined by a commercial ELISA kit purchased from Abcam, Inc. (Cambridge, United Kingdom, Product No. ab100722). The color generated was determined by measuring the OD value at $450 \mathrm{~nm}$ with a spectrophotometric microtiter plate reader (Molecular Devices Corp., Sunnyvale, CA).

\section{Western blot analysis}

Total proteins of kidney tissues were extracted with a solution (Pro-Prep Protein Extraction Solution; Intron Biotechnology, Gyeonggi-Do, Korea) according to the manufacturer's instructions. The proteins were separated by sodium dodecyl sulfate-polyacrylamide gel electrophoresis (SDS-PAGE), transferred to nitrocellulose membranes, and detected with primary antibodies: SOD1 (1:1000; Assay Designs, Ann Arbor, MI, Product No. ADI-SOD-100); SOD2 (1:10,000; Abcam, Product No. 16956), total-AMPK (1:2000, Product No. 2532), phospho-Thr ${ }^{172}$ AMPK (1:2000, Product No. 2535), totalFoxO1 (1:1000, Product No. 2880), phospho-Ser ${ }^{256}$ FoxO1 (1:1000, Product No. 9461), total-FoxO3a (1:1000, Product No. 2497), phospho-Ser ${ }^{253}$ FoxO3a (1:1000, Product No. 9466), HO-1 (1:2000, Product No. 5061), lamin B1 (1:2000; Cell Signaling Technology, Danvers, MA, Product No. 12586), PGC-1 $\alpha$ (1:2000; Novus Biologicals, Littleton, CO, Product No. NB100-60955), SOD3 (1:5000; Santa Cruz Biotechnology, Inc., Santa Cruz, CA, Product No. sc-67089), Nrf2 (1:1000,
Product No. sc-722), Keap1 (1:1000, Product No. sc-33569), NQO-1 (1:2000, Product No. sc-16464), Nox1 (1:500, Product No. sc-25545), Nox4 (1:500, Product No. sc-30141), arginase I (1:3000, Product No. sc-271430), arginase II (1:3000, Product No. sc-393496), BCL-2 (1:500, Product No. sc-492), BAX (1:500, Product No. sc-493), CD68 (1:2000; Bio-Rad Laboratories, Irvine, CA, Product No. MCA1957), Gr-1 (1:3000, Product No. MCA2387), iNOS/NO (1:2000, BD Biosciences, San Diego, CA, Product No. 610328), Nox2 (1:2000, Product No. 611415), and $\beta$-actin (1:10,000; Sigma-Aldrich, St Louis, MO, Product No. A5441). After washing, the membrane was incubated with antimouse IgG or antirabbit IgG, HRP-linked secondary antibody (Cell Signaling Technology, Product Nos. 7076, 7074), or antigoat IgG HRP-peroxidase antibody produced in rabbit (Sigma-Aldrich, Product No. A54020). Antibody binding was observed by chemiluminescence (ECL Plus; GE Healthcare Bio-Science, Piscataway, NJ) and detected by a Vilber chemiluminescence analyzer (Fusion SL 4; Vilber Lourmat, Marne-la-Vallée, France). The density of each band was quantified with Quantity One software (Bio-Rad Laboratory, Hercules, CA).

\section{Semiquantitative RT-PCR analysis}

We extracted total RNA from kidney tissues with TRIZOL reagent (Invitrogen, Carlsbad, CA, Product No. 15596026), according to the manufacturer's instructions. RT-PCR experiments were carried out with cDNAs generated from $2 \mu \mathrm{g}$ of total RNA using a GeneAmp ${ }^{\mathrm{TM}}$ RNA PCR Core Kit (Applied Biosystems, Foster City, CA, Product No. N8080143). The RT-PCR exponential phase was determined on 30-35 cycles to allow semiquantitative comparisons of cDNAs developed from identical reactions with GoTaq ${ }^{\circledR}$ Green Master Mix (Promega, Madison, WI, Product No. M7122). The 18S rRNA was used as an endogenous control gene. Primers used for AMPK $\alpha 1, \mathrm{AMPK} \alpha 2, \mathrm{PGC}-1 \alpha$, and Nrf 2 are shown in Table 2.

\section{In vitro study}

The HGECs (Angio-Proteomie, Boston, MA, Product No. cAP-0004) were cultured in Endogrowth medium (AngioProteomie). Passages 4-8 were used in all experiments.

Table 2. Primer Sequences for Reverse Transcription Polymerase Chain Reaction Analysis

\begin{tabular}{ll}
\hline Gene & \multicolumn{1}{c}{ Sequence } \\
\hline$A M P K \alpha 1$ & Fwd: GTCAAAGCCGACCCAATGATA \\
& Rev: CGTACACGCAAATAATAGGGGTT \\
$A M P K \alpha 2$ & Fwd: CAGGCCATAAAGTGGCAGTTA \\
& Rev: AAAAGTCTGTCGGAGTGCTGA \\
$P G C-1 \alpha$ & Fwd: AGAGCAAGTATGACTCTCTGG \\
& Rev: GTCCTCACATGTGTACATATG \\
$N r f 2$ & Fwd: TTGGCAGAGACATTCCCAT \\
$18 s r R N A$ & Rev: GCTGCCACCGTCACTGGG \\
& Fwd: CGCGGTTCTATTTTGTTGGT \\
& Rev: AGTCGGCATCGTTTATGGTC
\end{tabular}

AMPK, adenosine monophosphate-activated protein kinase; Fwd, forward; Nrf2, nuclear factor E2-related factor 2; PGC-1 $\alpha$, peroxisome proliferative-activated receptor $\gamma$ coactivator $1 \alpha$; Rev, reverse; RNA, ribonucleic acid. 
HGECs were exposed to LG ( $5 \mathrm{mmol} / \mathrm{L}$ D-glucose) or HG ( $35 \mathrm{mmol} / \mathrm{L} \mathrm{D}$-glucose) with or without additional $24 \mathrm{~h}$ administration of hEC-SOD $(0.025,0.1$, or $0.25 \mathrm{U} / \mathrm{mL})$. siRNA targeted to $A M P K \alpha 1$ and $A M P K \alpha 2$ and scrambled siRNA (siRNA cont) were complexed with transfection reagent (Lipofectamin 2000; Invitrogen). The sequences of siRNAs are as follows: $\alpha 1$-AMPK, GCAUAUGCUGCAGGUAGAU and $\alpha 2$-AMPK, CGUCAUUGAUGAUGAGGCU (Bioneer, Daejeon, Korea). The HGECs in six-well plates were transfected with $50 \mathrm{n} M \alpha 1-$ and $\alpha 2$-AMPK siRNAs for $24 \mathrm{~h}$ by transfection reagent in Opti-MEM medium (Gibco BRL, Grand Island, NY). After transfection, cells were treated with hEC-SOD in HG medium to evaluate the effects of siRNA on HGECs.

\section{Statistical analysis}

The data are expressed as mean \pm standard deviation. Multiple comparisons were performed using ANOVA with Bonferroni correction and SPSS 21.0 software (IBM, NY). A $p$ value $<0.05$ was considered a statistically significant difference.

\section{Acknowledgments}

This study was supported by grants from the Basic Science Research Program through the National Research Foundation of Korea (NRF) funded by the Ministry of Education, Science, and Technology (J.H.L.: 2015R1D1A1A01056984, H.W.K.: 2016 R1A2B2015878, C.W.P.: 2016R1A2B2015980) and by the Korea Health Technology R\&D Project through the Korea Health Industry Development Institute (KHIDI) funded by the Ministry of Health \& Welfare, Republic of Korea (T.W.K.: HI17C0616).

\section{Author Disclosure Statement}

No competing financial interests exist for any author. All authors declare that there is no duality of interest associated with this article.

\section{References}

1. Aquilano K, Baldelli S, Pagliei B, Cannata SM, Rotilio G, and Ciriolo MR. p53 orchestrates the PGC-1alphamediated antioxidant response upon mild redox and metabolic imbalance. Antioxid Redox Signal 18: 386-399, 2013.

2. Arellano-Buendia AS, Tostado-Gonzalez M, Garcia-Arroyo FE, Cristobal-Garcia M, Loredo-Mendoza ML, Tapia E, Sanchez-Lozada LG, and Osorio-Alonso H. Anti-inflammatory therapy modulates Nrf2-Keap1 in kidney from rats with diabetes. Oxid Med Cell Longev 2016: 4693801, 2016.

3. Awad AS, You H, Gao T, Cooper TK, Nedospasov SA, Vacher J, Wilkinson PF, Farrell FX, and Brian Reeves W. Macrophage-derived tumor necrosis factor-alpha mediates diabetic renal injury. Kidney Int 88: 722-733, 2015.

4. Bondeva T and Wolf G. Reactive oxygen species in diabetic nephropathy: friend or foe? Nephrol Dial Transplant 29: 1998-2003, 2014.

5. Canto C and Auwerx J. PGC-1alpha, SIRT1 and AMPK, an energy sensing network that controls energy expenditure. Curr Opin Lipidol 20: 98-105, 2009.

6. Chu Y, Piper R, Richardson S, Watanabe Y, Patel P, and Heistad DD. Endocytosis ofextracellular superoxide dismutase into endothelial cells: role of the heparin-binding domain. Arterioscler Thromb Vasc Biol 26: 1985-1990, 2006.
7. Dugan LL, You YH, Ali SS, Diamond-Stanic M, Miyamoto S, DeCleves AE, Andreyev A, Quach T, Ly S, Shekhtman G, Nguyen W, Chepetan A, Le TP, Wang L, Xu M, Paik KP, Fogo A, Viollet B, Murphy A, Brosius F, Naviaux RK, and Sharma K. AMPK dysregulation promotes diabetesrelated reduction of superoxide and mitochondrial function. J Clin Invest 123: 4888-4899, 2013.

8. Fattman CL, Schaefer LM, and Oury TD. Extracellular superoxide dismutase in biology and medicine. Free Radic Biol Med 35: 236-256, 2003.

9. Folz RJ, Guan J, Seldin MF, Oury TD, Enghild JJ, and Crapo JD. Mouse extracellular superoxide dismutase: primary structure, tissue-specific gene expression, chromosomal localization, and lung in situ hybridization. Am J Respir Cell Mol Biol 17: 393-403, 1997.

10. Forbes JM, Coughlan MT, and Cooper ME. Oxidative stress as a major culprit in kidney disease in diabetes. Diabetes 57: 1446-1454, 2008.

11. Fridovich I. Superoxide anion radical (O2-.), superoxide dismutases, and related matters. J Biol Chem 272: 1851518517, 1997.

12. Fu J, Lee K, Chuang PY, Liu Z, and He JC. Glomerular endothelial cell injury and cross talk in diabetic kidney disease. Am J Physiol Renal Physiol 308: F287-F297, 2015.

13. Fujita H, Fujishima H, Chida S, Takahashi K, Qi Z, Kanetsuna Y, Breyer MD, HarrisRC, Yamada Y, and Takahashi T. Reduction of renal superoxide dismutase in progressive diabetic nephropathy. J Am Soc Nephrol 20: 1303-1313, 2009.

14. Fujita H, Fujishima H, Takahashi K, Sato T, Shimizu T, Morii T, Shimizu T, Shirasawa T, Qi Z, Breyer MD, Harris RC, Yamada Y, and Takahashi T. SOD1, but not SOD3, deficiency accelerates diabetic renal injury in C57BL/6Ins2(Akita) diabetic mice. Metabolism 61: 1714-1724, 2012.

15. Fukuda M, Nakamura T, Kataoka K, Nako H, Tokutomi Y, Dong YF, Ogawa H, and Kim-Mitsuyama S. Potentiation by candesartan of protective effects of pioglitazone against type 2 diabetic cardiovascular and renal complications in obese mice. J Hypertens 28: 340-352, 2010.

16. Giugliano D, Ceriello A, and Paolisso G. Oxidative stress and diabetic vascular complications. Diabetes Care 19: 257-267, 1996.

17. Greer EL, Oskoui PR, Banko MR, Maniar JM, Gygi MP, Gygi SP, and Brunet A. The energy sensor AMP-activated protein kinase directly regulates the mammalian FOXO3 transcription factor. J Biol Chem 282: 30107-30119, 2007.

18. Hardie DG, Ross FA, and Hawley SA. AMPK: a nutrient and energy sensor that maintains energy homeostasis. Nat Rev Mol Cell Biol 13: 251-262, 2012.

19. Hasegawa G, Nakano K, Sawada M, Uno K, Shibayama Y, Ienaga K, and Kondo M. Possible role of tumor necrosis factor and interleukin-1 in the development of diabetic nephropathy. Kidney Int 40: 1007-1012, 1991.

20. Hong YA, Lim JH, Kim MY, Kim TW, Kim Y, Yang KS, Park HS, Choi SR, Chung S, Kim HW, Kim HW, Choi BS, Chang YS, and Park CW. Fenofibrate improves renal lipotoxicity through activation of AMPK-PGC-1alpha in $\mathrm{db} /$ db mice. PLoS One 9: e96147, 2014.

21. Jager S, Handschin C, St-Pierre J, and Spiegelman BM. AMP-activated protein kinase (AMPK) action in skeletal muscle via direct phosphorylation of PGC-1alpha. Proc Natl Acad Sci U S A 104: 12017-12022, 2007.

22. Jha JC, Banal C, Chow BS, Cooper ME, and JandeleitDahm K. Diabetes and kidney disease: role of oxidative stress. Antioxid Redox Signal 25: 657-684, 2016. 
23. Jin DC, Yun SR, Lee SW, Han SW, Kim W, Park J, and Kim YK. Lessons from 30 years' data of Korean end-stage renal disease registry, 1985-2015. Kidney Res Clin Pract 34: 132-139, 2015.

24. Kashihara N, Haruna Y, Kondeti VK, and Kanwar YS. Oxidative stress in diabetic nephropathy. Curr Med Chem 17: 4256-4269, 2010.

25. Kim HJ and Vaziri ND. Contribution of impaired Nrf2Keap1 pathway to oxidative stress and inflammation in chronic renal failure. Am J Physiol Renal Physiol 298: F662-F671, 2010.

26. Kim MY, Lim JH, Youn HH, Hong YA, Yang KS, Park HS, Chung S, Koh SH, Shin SJ, Choi BS, Kim HW, Kim YS, Lee JH, Chang YS, and Park CW. Resveratrol prevents renal lipotoxicity and inhibits mesangial cell glucotoxicity in a manner dependent on the AMPKSIRT1-PGC1alpha axis in $\mathrm{db} / \mathrm{db}$ mice. Diabetologia 56: 204-217, 2013.

27. Kim Y and Park CW. Adenosine monophosphate-activated protein kinase in diabetic nephropathy. Kidney Res Clin Pract 35: 69-77, 2016.

28. Kimura F, Hasegawa G, Obayashi H, Adachi T, Hara H, Ohta M, Fukui M, KitagawaY, Park H, Nakamura N, Nakano K, and Yoshikawa T. Serum extracellular superoxide dismutase in patients with type 2 diabetes: relationship to the development of micro- and macrovascular complications. Diabetes Care 26: 1246-1250, 2003.

29. Koh ES, Lim JH, Kim MY, Chung S, Shin SJ, Choi BS, Kim HW, Hwang SY, KimSW, Park CW, and Chang YS. Anthocyanin-rich Seoritae extract ameliorates renal lipotoxicity via activation of AMP-activated protein kinase in diabetic mice. J Transl Med 13: 203, 2015.

30. Kulkarni SR, Donepudi AC, Xu J, Wei W, Cheng QC, Driscoll MV, Johnson DA, Johnson JA, Li X, and Slitt AL. Fasting induces nuclear factor E2-related factor 2 and ATPbinding Cassette transporters via protein kinase A and Sirtuin-1 in mouse and human. Antioxid Redox Signal 20: 15-30, 2014.

31. Kuo CW, Shen CJ, Tung YT, Chen HL, Chen YH, Chang WH, Cheng KC, Yang SH, and Chen CM. Extracellular superoxide dismutase ameliorates streptozotocin-inducedrat diabetic nephropathy via inhibiting the ROS/ERK1/2 signaling. Life Sci 135: 77-86, 2015.

32. Kwon MJ, Han J, Kim BH, Lee YS, and Kim TY. Superoxide dismutase 3 suppresses hyaluronic acid fragments mediated skin inflammation by inhibition of toll-like receptor 4 signaling pathway: superoxide dismutase 3 inhibits reactive oxygen species-induced trafficking of toll-like receptor 4 to lipid rafts. Antioxid Redox Signal 16: 297-313, 2012.

33. Kwon MJ, Jeon YJ, Lee KY, and Kim TY. Superoxide dismutase 3 controls adaptive immune responses and contributes to the inhibition of ovalbumin-induced allergic airway inflammation in mice. Antioxid Redox Signal 17: 1376-1392, 2012.

34. Laatikainen LE, Incoronato M, Castellone MD, Laurila JP, Santoro M, and Laukkanen MO. SOD3 decreases ischemic injury derived apoptosis through phosphorylation of Erk1/ 2, Akt, and FoxO3a. PLoS One 6: e24456, 2011.

35. Lee J and Kim S. Upregulation of heme oxygenase-1 expression by dehydrodiconiferylalcohol (DHCA) through the AMPK-Nrf2 dependent pathway. Toxicol Appl Pharmacol 281: 87-100, 2014.

36. Lee YS, Cheon IS, Kim BH, Kwon MJ, Lee HW, and Kim TY. Loss of extracellularsuperoxide dismutase induces severe IL-23-mediated skin inflammation in mice. J Invest Dermatol 133: 732-741, 2013.

37. Liu XM, Peyton KJ, Shebib AR, Wang H, Korthuis RJ, and Durante W. Activation of AMPK stimulates heme oxygenase1 gene expression and human endothelial cell survival. Am J Physiol Heart Circ Physiol 300: H84-H93, 2011.

38. Mason RM and Wahab NA. Extracellular matrix metabolism in diabetic nephropathy. J Am Soc Nephrol 14: 13581373, 2003.

39. Nguyen T, Nioi P, and Pickett CB. The Nrf2-antioxidant response element signaling pathway and its activation by oxidative stress. J Biol Chem 284: 13291-13295, 2009.

40. Ohta $\mathrm{H}$, Adachi $\mathrm{T}$, and Hirano K. Internalization of human extracellular-superoxide dismutase by bovine aortic endothelial cells. Free Radic Biol Med 16: 501-507, 1994.

41. Salminen A and Kaarniranta K. AMP-activated protein kinase (AMPK) controls the aging process via an integrated signaling network. Ageing Res Rev 11: 230-241, 2012.

42. Sharma K. Obesity and diabetic kidney disease: role of oxidant stress and redox balance. Antioxid Redox Signal 25: 208-216, 2016.

43. St-Pierre J, Drori S, Uldry M, Silvaggi JM, Rhee J, Jager S, Handschin C, Zheng K, Lin J, Yang W, Simon DK, Bachoo $\mathrm{R}$, and Spiegelman BM. Suppression of reactive oxygen species and neurodegeneration by the PGC-1 transcriptional coactivators. Cell 127: 397-408, 2006.

44. Stralin P, Karlsson K, Johansson BO, and Marklund SL. The interstitium of the human arterial wall contains very large amounts of extracellular superoxide dismutase. Arterioscler Thromb Vasc Biol 15: 2032-2036, 1995.

45. Tan RJ, Zhou D, Xiao L, Zhou L, Li Y, Bastacky SI, Oury TD, and Liu Y. Extracellular superoxide dismutase protects against proteinuric kidney disease. J Am Soc Nephrol 26: 2447-2459, 2015.

46. Tesch GH. MCP-1/CCL2: a new diagnostic marker and therapeutic target for progressive renal injury in diabetic nephropathy. Am J Physiol Renal Physiol 294: F697-F701, 2008.

47. Yang Y, Chen G, Cheng X, Teng Z, Cai X, Yang J, Sun X, Lu W, Wang X, Yao Y, Hu C, and Cao P. Therapeutic potential of digitoflavone on diabetic nephropathy: nuclear factor erythroid 2-related factor 2-dependent anti-oxidant and anti-inflammatory effect. Sci Rep 5: 12377, 2015.

48. Zrelli H, Matsuoka M, Kitazaki S, Zarrouk M, and Miyazaki $\mathrm{H}$. Hydroxytyrosol reduces intracellular reactive oxygen species levels in vascular endothelial cells by upregulating catalase expression through the AMPK-FOXO3a pathway. Eur J Pharmacol 660: 275-282, 2011.

Address correspondence to: Dr. Cheol Whee Park Division of Nephrology Department of Internal Medicine The Catholic University of Korea 222, Banpo-Daero, Seocho-Gu Seoul 06591 Republic of Korea

E-mail: cheolwhee@hanmail.net

Date of first submission to ARS Central, July 8, 2017; date of final revised submission, September 10, 2017; date of acceptance, October 10, 2017. 


$\begin{aligned} & \text { Abbreviations Used } \\ \text { 8-OH-dG }= & \text { 8-hydroxy-2'-deoxyguanosine } \\ \text { AMPK }= & \text { adenosine monophosphate-activated } \\ & \text { protein kinase } \\ \text { BAX }= & \text { BCL-2-associated } \mathrm{X} \\ \mathrm{BCL}-2 & =\text { B cell leukemia/lymphoma } 2 \\ \mathrm{DN} & =\text { diabetic nephropathy } \\ \mathrm{EC}-\mathrm{SOD} & =\text { extracellular superoxide dismutase } \\ \mathrm{F} 4 / 80 & =\text { cell surface glycoprotein F4/80 } \\ \mathrm{FOXO} & =\text { forkhead box O transcription factor } \\ \mathrm{Gr}-1 & =\text { granulocyte-differentiation antigen-1 } \\ \mathrm{hEC}-\mathrm{SOD}= & \text { human recombinant extracellular } \\ \mathrm{HG} & =\text { high glucose } \\ \mathrm{HGEC} & =\text { human glomerular endothelial cell } \\ \mathrm{HO}-1 & =\text { heme oxygenase-1 } \\ \mathrm{HPLC} & =\text { high performance liquid chromatography } \\ \mathrm{IL} & =\text { interleukin } \\ \mathrm{iNOS} & =\text { inducible nitric oxide synthase } \\ \mathrm{Keap} 1 & =\text { Kelch-like ECH-associated protein } 1 \\ \mathrm{LG} & =\text { low glucose }\end{aligned}$

MCP-1 = monocyte chemoattractant protein-1 Nox $=$ NADPH oxidase

NQO-1 $=$ NAD $(\mathrm{P}) \mathrm{H}$ dehydrogenase 1

$\mathrm{Nrf} 2=$ nuclear factor E2-related factor 2

$\mathrm{PAS}=$ periodic acid-Schiff

PGC- $1 \alpha=$ peroxisome proliferative-activated receptor $\gamma$ coactivator $1 \alpha$

$\mathrm{ROS}=$ reactive oxygen species

$\mathrm{RNS}=$ reactive nitrogen species

$\mathrm{RT}-\mathrm{PCR}=$ reverse transcription polymerase chain reaction

SDS-PAGE $=$ sodium dodecyl sulfate-polyacrylamide gel electrophoresis

siRNA $=$ small interfering ribonucleic acid

$\mathrm{SOD}=$ superoxide dismutase

$\mathrm{TEM}=$ transmission electron microscopy

TGF- $\beta 1=$ transforming growth factor- $\beta 1$

TNF- $\alpha=$ tumor necrosis factor- $\alpha$

TUNEL $=$ terminal deoxynucleotidyl transferase-mediated dUTP nick end-labeling 